\title{
Trk Activation of the ERK1/2 Kinase Pathway Stimulates Intermediate Chain Phosphorylation and Recruits Cytoplasmic Dynein to Signaling Endosomes for Retrograde Axonal Transport
}

\author{
David J. Mitchell, ${ }^{1 \star}$ Kiev R. Blasier, ${ }^{1 \star}$ Erin D. Jeffery, ${ }^{2}$ Mitchell W. Ross, ${ }^{1}$ Ashok K. Pullikuth, ${ }^{4}$ Dong Suo, ${ }^{3}$ Juyeon Park, ${ }^{3}$ \\ W. Russell Smiley, ${ }^{1}$ Kevin W.-H. Lo, ${ }^{1}$ Jeffrey Shabanowitz, ${ }^{2}$ Christopher D. Deppmann, ${ }^{3}$ Jonathan C. Trinidad, ${ }^{5}$ \\ Donald F. Hunt, ${ }^{2}$ Andrew D. Catling, ${ }^{4}$ and K. Kevin Pfister ${ }^{1}$ \\ ${ }^{1}$ Department of Cell Biology, University of Virginia, Charlottesville, VA 22908, Departments of ${ }^{2}$ Chemistry and ${ }^{3}$ Biology, University of Virginia, \\ Charlottesville, VA 22904, ${ }^{4}$ Department of Pharmacology and Experimental Therapeutics, Louisiana State University Health Sciences Center, New Orleans, \\ Louisiana 70112, and ${ }^{5}$ Department of Pharmaceutical Chemistry, University of California, San Francisco, San Francisco, CA 94158
}

\begin{abstract}
The retrograde transport of Trk-containing endosomes from the axon to the cell body by cytoplasmic dynein is necessary for axonal and neuronal survival. We investigated the recruitment of dynein to signaling endosomes in rat embryonic neurons and PC12 cells. We identified a novel phosphoserine on the dynein intermediate chains (ICs), and we observed a time-dependent neurotrophin-stimulated increase in intermediate chain phosphorylation on this site in both cell types. Pharmacological studies, overexpression of constitutively active MAP kinase kinase, and an in vitro assay with recombinant proteins demonstrated that the intermediate chains are phosphorylated by the MAP kinase ERK1/2, extracellular signal-regulated kinase, a major downstream effector of Trk. Live cell imaging with fluorescently tagged IC mutants demonstrated that the dephosphomimic mutants had significantly reduced colocalization with Trk and Rab7, but not a mitochondrial marker. The phosphorylated intermediate chains were enriched on immunoaffinity-purified Trk-containing organelles. Inhibition of ERK reduced the amount of phospho-IC and the total amount of dynein that copurified with the signaling endosomes. In addition, inhibition of ERK1/2 reduced the motility of Rab7- and TrkB-containing endosomes and the extent of their colocalization with dynein in axons. NGF-dependent survival of sympathetic neurons was significantly reduced by the overexpression of the dephosphomimic mutant IC-1B-S80A, but not WT IC-1B, further demonstrating the functional significance of phosphorylation on this site. These results demonstrate that neurotrophin binding to Trk initiates the recruitment of cytoplasmic dynein to signaling endosomes through ERK1/2 phosphorylation of intermediate chains for their subsequent retrograde transport in axons.
\end{abstract}

\section{Introduction}

Axonal neurotrophin receptor kinases, Trks, play important roles in neuronal survival (Miller and Kaplan, 2001; Ginty and Segal, 2002; Huang and Reichardt, 2003; Howe and Mobley, 2005). Upon neurotrophin binding to the Trks, they are internalized in

Received Nov. 7, 2011; revised Aug. 14, 2012; accepted Sept. 8, 2012.

Author contributions: E.D.J., J.S., C.D.D., J.C.T., D.F.H., A.D.C., and K.K.P. designed research; D.J.M., K.R.B., E.D.J., M.W.R., A.K.P., D.S., J.P., W.R.S., K.W.-H.L., J.C.T., and A.D.C. performed research; K.W.-H.L. contributed unpublished reagents/analytic tools;D.J.M., K.R.B., E.D.J., M.W.R., A.K.P., D.S., J.P., W.R.S., J.S., C.D.D., J.C.T., D.F.H., A.D.C., and K.K.P. analyzed data; K.K.P. wrote the paper.

This work was supported by NIH-National Institute of General Medical Science (NIGMS) Grants R01 GM086472 (K.K.P.) and R01 GM068111 (A.D.C.), a Louisiana State University Health Sciences (enter Research Enhancement Fund award (A.D.C.), NIH Grant GM37537 and National Center for Research Resources Grant P41 RR001614 (D.F.H.), and the Sloan Foundation, the University of Virginia Fund for Excellence in Science and Technology, and NIH-NINDS Grant R01 NS072388 (C.D.D.). We thank George Bloom and Bettina Winckler for critically reading this manuscript.

${ }^{*}$ D.J.M. and K.R.B. contributed equally to this work.

The authors declare no competing financial interests.

Correspondence should be addressed to Dr. K. Kevin Pfister, Cell Biology Department, School of Medicine, University of Virginia, P.0. BOX 800732, Charlottesville, VA 22908. E-mail: kkp9w@virginia.edu.

J. C. Trinidad's present address: Department of Chemistry, Indiana University, Bloomington, IN 47405.

DOI:10.1523/JNEUROSCI.5599-11.2012

Copyright $\odot 2012$ the authors $\quad 0270-6474 / 12 / 3215495-16 \$ 15.00 / 0$ signaling endosomes. The retrograde transport of the endosomes to the cell body by cytoplasmic dynein is essential for the signaling required for axonal and neuronal survival (Heerssen et al., 2004; Wu et al., 2007). Dynein is also responsible for the retrograde axonal transport of other cargos including lysosomes, mitochondria, viruses, and neurofilaments (Vallee et al., 2004; He et al., 2005; Leopold and Pfister, 2006; Uchida et al., 2009). In addition, cytoplasmic dynein is transported as an organelleassociated cargo in the anterograde direction (Dillman and Pfister, 1994; Ha et al., 2008; Hirokawa et al., 2010).

Considerable information is known about the mechanisms used to regulate binding of kinesin family members to membrane-bounded organelles, including Trk carrier vesicles for anterograde transport into the axon (Morfini et al., 2002; Gomes et al., 2006; Arimura et al., 2009; Ascaño et al., 2009; Hirokawa et al., 2010; Huang et al., 2011). Less is known about the regulation of cytoplasmic dynein during anterograde and retrograde axonal transport (Kardon and Vale, 2009; Akhmanova and Hammer, 2010). We used live cell imaging of fluorescently tagged proteins to study the recruitment of dynein to signaling endosomes in rat 
embryonic neurons and pheochromocytoma (PC12) cells (Ha et al., 2008). Dynein is a large protein complex with six subunits. The motor domain is a single subunit (Pfister et al., 2006). Two of the subunits, DYNC1I [the intermediate chain (IC)] and DYNC1LI (the light intermediate chain), have been implicated in dynein binding to membrane-bounded organelles (Niclas et al., 1996; Steffen et al., 1997; Vallee et al., 2004; Pfister et al., 2006). We demonstrated previously that neurons and PC12 cells recruit different dynein complexes, as defined by their different IC isoforms, to Trk-containing organelles. We also found that neuronal dynein was phosphorylated, and that after the addition of nerve growth factor (NGF) to PC12 cells, the level of dynein IC phosphorylation increased (Dillman and Pfister, 1994; Salata et al., 2001).

The Trk receptor kinase is upstream of several major kinase signaling pathways (Huang and Reichardt, 2003). Therefore, we sought to determine whether Trk-dependent IC phosphorylation regulated dynein binding to signaling endosomes. We identified a novel conserved phosphoserine on IC- 1 and IC- 2 isolated from embryonic neurons and PC12 cells and found that the level of phosphorylation is dependent on neurotrophin and Trk kinase activity. The ICs are phosphorylated by the MAP kinase ERK1/2, one of the major downstream effectors of Trk. Live cell imaging of fluorescent wild-type (WT) and mutant intermediate chains, and biochemical analyses of purified Trk-containing organelles, demonstrated that phosphorylation at this site enhances dynein binding to endosomes, but not binding to mitochondria. These data reveal a mechanism by which Trk regulates the retrograde transport of its signaling endosome to promote neuron survival.

\section{Materials and Methods}

\section{Cell culture and transfection}

Rat pheochromocytoma (PC12) cells were cultured as described previously (Ha et al., 2008), except that medium for undifferentiated cells was supplemented with 5\% FBS and 10\% FCS (Hyclone). For colocalization studies, PC12 cells were cotransfected with the siRNA nucleotide to the $3^{\prime}$ UTR of the IC-2C gene, TrkA-GFP, and IC-2C-monomeric RFP (mRFP) wild-type or mutant plasmids by electroporation using Nucleofector Kit $\mathrm{V}$ and program U-029 (Lonza). Approximately two million cells were used per transfection. Rat embryonic cortical and hippocampal neurons [embryonic day 17 (E17)-E19, of either sex] were prepared as described previously (Goslin et al., 1998; Ha et al., 2008) except that the cells were inverted on 25-mm-diameter coverslips in Neurobasal medium supplemented with B-27 and Glutamax (Invitrogen) without glia (Brewer et al., 1993). Embryonic E17-E19 cortical and hippocampal neurons in suspension were transfected with siRNA oligonucleotides to the UTR regions of IC-1 or IC-2 using electroporation with the Rat Neuron Kit and setting O-030; $\sim 5.5$ million cortical neurons were used per transfection and were plated for biochemical assays on a $6 \mathrm{~cm}$ dish, and 4 million hippocampal neurons/transfection were plated on two $6 \mathrm{~cm}$ dishes containing coverslips. Neurons grown on coverslips for 3-6 $\mathrm{d}$ in vitro (DIV) were transfected with fluorescent-tagged proteins for live cell imaging using the $\mathrm{CaPO}_{4}$ for Mammalian Cells Transfection Kit (Clontech) and the method used by Jiang and Chen (2006).

\section{Time course of neurotrophin stimulation}

PC12 cells were grown on $6 \mathrm{~cm}$ dishes coated with poly-L-lysine. NGF was added to the medium at $4 \mathrm{~nm}$ final concentration, and the cells were incubated at $37^{\circ} \mathrm{C}$ for $5-60 \mathrm{~min}$. The dishes were washed two times with $1 \times$ PBS and then the cells were incubated on an ice slurry for $5 \mathrm{~min}$ in lysis buffer [50 mм Tris, pH 8.1, 5 mм EDTA, 150 mм NaCl, 1.0\% Triton $\mathrm{X}-100,2 \mathrm{~mm}$ PMSF, $10 \mu \mathrm{g} / \mathrm{ml}$ leupeptin and pepstatin, $10 \mathrm{~mm}$ benzamidine, $1 \mu \mathrm{l} / \mathrm{ml}$ Phosphatase Inhibitor Cocktail II (Sigma), $20 \mathrm{~nm}$ calyculin, and $200 \mathrm{~nm}$ staurosporine]. The cells were scraped from the dishes, and the samples were spun at $4^{\circ} \mathrm{C}$ for $5 \mathrm{~min}$ at $10,000 \mathrm{rpm}$. The supernatant was removed and mixed with SDS-PAGE sample buffer. Embryonic cor- tical neurons were plated on poly-L-lysine-coated $6 \mathrm{~cm}$ dishes at $2.5 \times$ $10^{6}$ cells/dish. For experiments with growth factor depletion, the dishes were washed three times in Neurobasal medium with Glutamax, but no B27 (growth factors), and incubated overnight. The next morning, the dishes were washed three times with Neurobasal medium only and incubated for an additional $2 \mathrm{~h}$ in $3 \mathrm{ml} /$ dish. Then, brain-derived neurotrophic factor $(\mathrm{BDNF})$ at $100 \mathrm{ng} / \mathrm{ml}$ final concentration was added for 5-60 min. The cells were washed and lysed as for PC12 cells. The control dishes did not have medium replacement. For some experiments, the function blocking anti-BDNF antibody was added at $1 \mu \mathrm{g} / \mathrm{ml}$ to the overnight and morning growth factor depletion incubations.

\section{Kinase inhibition}

PC12 cells were grown on poly-L-lysine-treated tissue culture dishes under regular culture conditions. The medium was removed and replaced with fresh serum-free medium containing the appropriate drug or DMSO as vehicle control, and the dishes were incubated for $30 \mathrm{~min}$ at $37^{\circ} \mathrm{C}$. Then the medium was replaced with fresh medium containing both the drug and $4 \mathrm{~nm}$ NGF and incubated for $30 \mathrm{~min}$ at $37^{\circ} \mathrm{C}$. The cells were lysed and gel samples prepared as described above. Embryonic cortical neurons were starved as described above, and after the $2 \mathrm{~h}$ incubation in fresh Neurobasal medium, the appropriate volume of drug or DMSO was added to the dishes. Thirty minutes later, BDNF was added to the dishes to a final concentration of 100 $\mathrm{ng} / \mathrm{ml}$. After $15 \mathrm{~min}$, all of the dishes were washed twice with PBS and lysed as for PC12 cells. The following kinase inhibitors were used: MAP kinase kinase 1 (MEK1)/MEK2, UO126 $\left(\mathrm{C}_{18} \mathrm{H}_{16} \mathrm{~N}_{6} \mathrm{~S}_{2}\right)$ at $10 \mu \mathrm{M}$ (Promega) and PD $184352\left(\mathrm{C}_{17} \mathrm{H}_{14} \mathrm{ClF}_{2} \mathrm{IN}_{2} \mathrm{O}_{2}\right)$ at $1 \mu \mathrm{M}$ (Santa Cruz Biotechnology); MEK1/ 2/5, PD 184352 at $10 \mu \mathrm{M}$; Trk, $\mathrm{K} 252 \mathrm{~A}\left(\mathrm{C}_{27} \mathrm{H}_{21} \mathrm{~N}_{3} \mathrm{O}_{5}\right)$ at $200 \mathrm{nM}$; Cdk, roscovitine at $1 \mu \mathrm{M}$; GSK3, $\mathrm{LiCl}$ at $10 \mathrm{~mm}$ and $\mathrm{AR}-\mathrm{A} 014418\left(\mathrm{C}_{12} \mathrm{H}_{12} \mathrm{~N}_{4} \mathrm{O}_{4} \mathrm{~S}\right)$ at 10 mM; PI3K, LY294002 $\left(\mathrm{C}_{19} \mathrm{H}_{17} \mathrm{NO}_{3}\right)$ at $50 \mu \mathrm{M}$; protein kinase A (PKA), KT5720 $\left(\mathrm{C}_{32} \mathrm{H}_{31} \mathrm{~N}_{3} \mathrm{O}_{5}\right)$ at $500 \mathrm{~nm}$; and PKC $(\alpha, \beta, \gamma, \delta)$, GÖ 6983 $\left(\mathrm{C}_{26} \mathrm{H}_{26} \mathrm{~N}_{4} \mathrm{O}_{3}\right)$ at $25 \mathrm{~nm}$ (all from Calbiochem).

\section{Kinase activation in vivo}

The effect of the activation of ERK1/2 on IC phosphorylation in PC12 cells was determined by cotransfecting cells with myc-tagged IC-2C and either constitutively active MEK [pCMV HA MEK1 (S218D, S222D)] or pCMV HA using electroporation. MEK is the immediate upstream activator of ERK1/2. Cotransfection with myc-IC-2C was used to compensate for the low efficiency of plasmid transfection into PC12 cells. The myc-IC-2C in the transfected cells was immunoprecipitated, and its phosphorylation level was analyzed by SDS-PAGE and Western blotting.

\section{Isolation of membrane-bound organelles}

Membrane-bound organelles were isolated from control and NGFstimulated PC12 cells using the method of Grimes et al. (1996) (Ha et al., 2008), except that $20 \mathrm{~nm}$ calyculin, $200 \mathrm{~nm}$ staurosporine, and $1 \mu \mathrm{l} / \mathrm{ml}$ Phosphatase Inhibitor Cocktail II (Sigma) were added to the lysis buffer. Trk-containing organelles were isolated by immunoaffinity and analyzed by SDS-PAGE and Western blotting as described previously (Ha et al., 2008). The relative amount of antibody staining on blots was quantified from high-resolution scans of films with exposures in the linear range of the signals. The intensities of the bands were quantified and corrected for background using MetaMorph7.

\section{Immunoprecipitation, SDS-PAGE, and Western blotting}

Endogenous dynein from whole rat brain lysate (either sex) and cortical neurons, or myc-tagged IC from transiently transfected PC12 cells, was immunoprecipitated on protein A-Sepharose-4B beads as described previously, using either 74.1, IC-1, or the 9E10 antibody to myc (Dillman and Pfister, 1994). SDS-PAGE and Western blotting were as described previously (Ha et al., 2008).

\section{In vitro phosphorylation}

Escherichia coli Rosetta (DE3) pLysS (Novagen) expressing rat IC-2C in pET 21a were grown, and IC-2C was purified as described previously (A. K. Pullikuth and A. D. Catling, unpublished observations). Briefly, bacterial lysates were clarified by centrifugation and loaded onto a $1 \mathrm{ml}$ HiTrap HP nickel column (GE Healthcare Life Sciences). The IC-2C was eluted with a linear gradient of 15-500 mm imidazole. Fractions contain- 


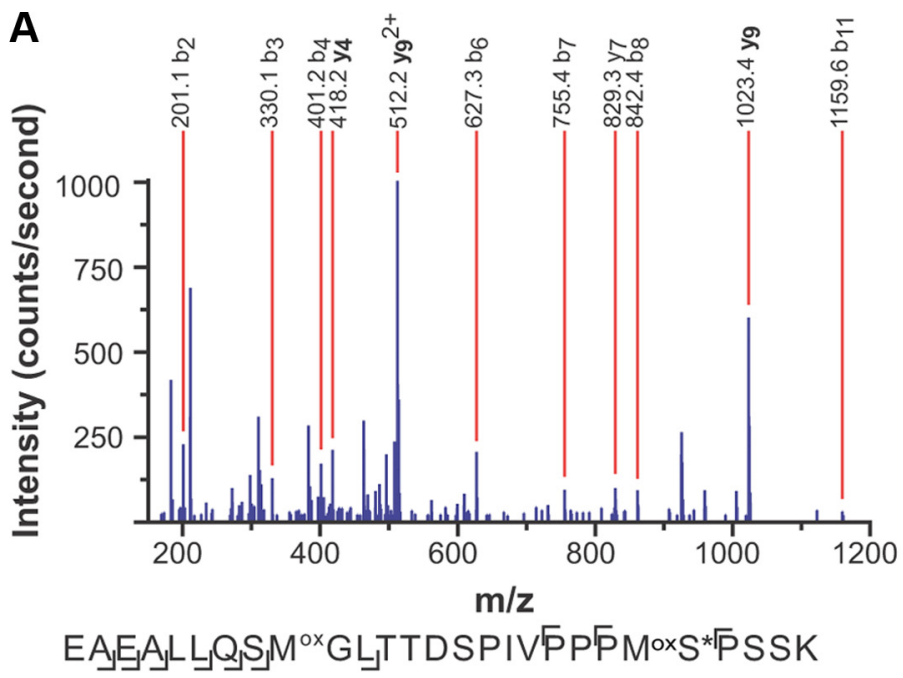

B IC Domains
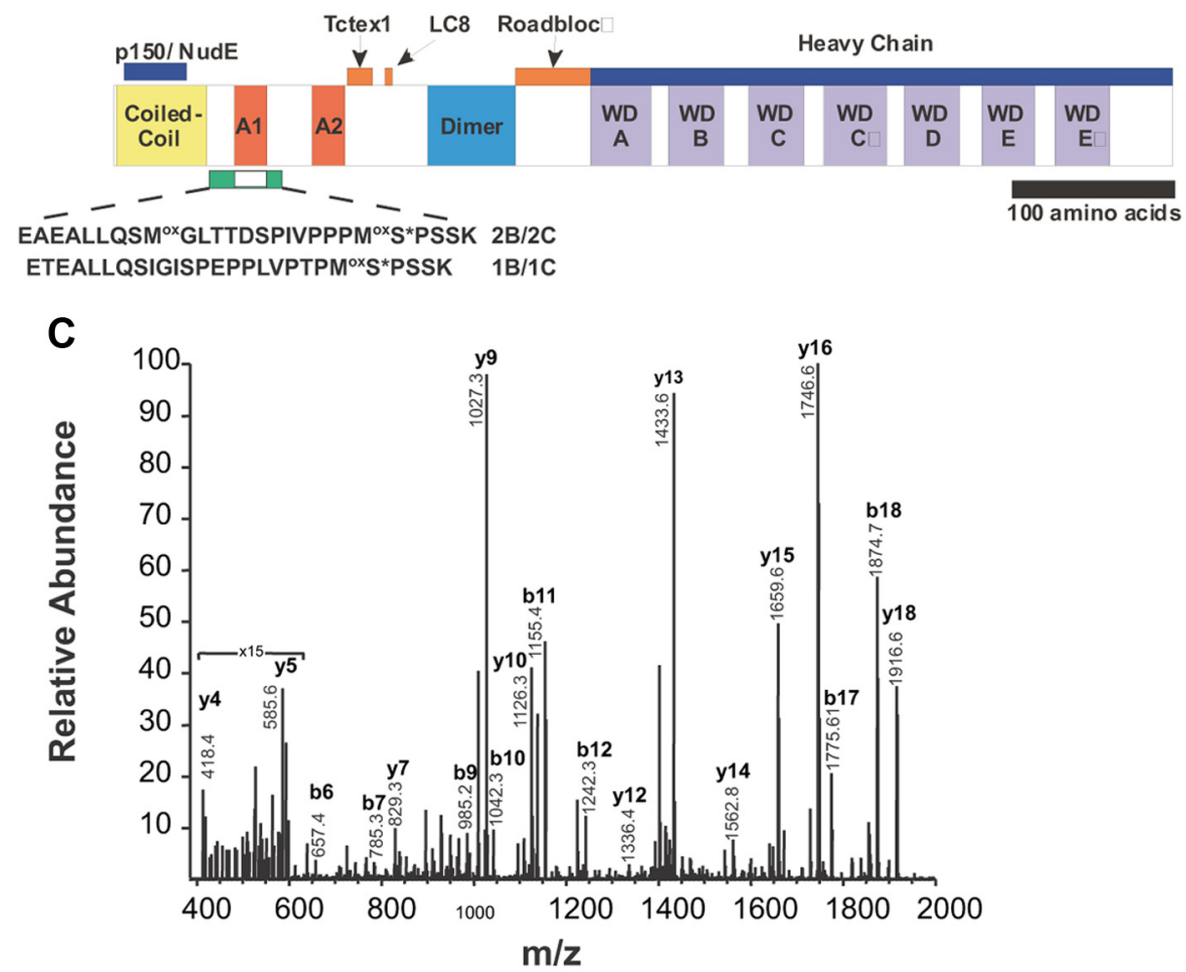

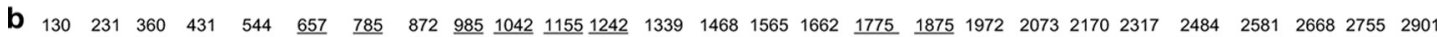

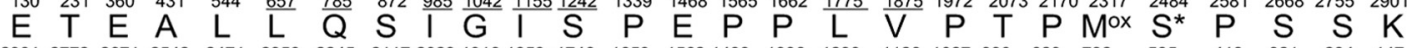

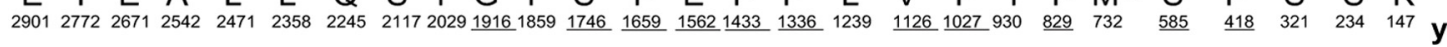

Figure 1. Identification of cytoplasmic dynein IC phosphorylation by mass spectrometry. A, Detection of a phosphorylation site on IC-2 in NGF-stimulated PC12 cells. MS/MS spectra analysis for the phosphorylated peptide EAEALLOSM ${ }^{0 \mathrm{G} G L T D S P I V P P P M}{ }^{0 x}{ }^{*}$ PSSK is shown. MS/MS was acquired on a triply charged peptide at $\mathrm{m} / \mathrm{z} 965.8$, corresponding to the singly phosphorylated version of the peptide with oxidation of both methionines. The fragments at $\mathrm{m} / \mathrm{z} 1023.4$ and 512.2 correspond to the singly and doubly charged phosphorylated versions of $\mathrm{y} 9$ (bold), respectively. This localized the site of phosphorylation to the nine C-terminal amino acids. The fragment at $\mathrm{m} / \mathrm{z} 418.2$ corresponds to the nonphosphorylated version of $y 4$ (bold). This excluded the four C-terminal amino acids as the site of modification. Therefore, serine 81 (IC-2C) is the site of phosphorylation. The phosphorylated serine is indicated with an asterisk. $B$, Location of the phosphorylation site on the intermediate chain domain map. The two alternative splicing regions are indicated as $\mathrm{A} 1$ and $\mathrm{A} 2$ (red). The green bar below the domain map shows the position of the neurotrophin-sensitive phosphopeptides found in the IC-2B, IC- 2 C, IC- $1 B$, and IC- 1 C isoforms and their amino acid sequences. The phosphorylated serines are indicated with asterisks. The phosphopeptide does not include the first alternative splice region (white gap in green bar), which is excised from the $A$ isoforms to make the B and Cisoforms. Further toward the IC N terminus is a coiled-coil region (yellow). Part of this region binds the p150 subunit of dynactin and/or NudE (blue bar above the domain map). There are seven WD repeats at the Cterminus (purple), which most likely form a $\beta$-propeller structure and bind the heavy chain. The regions that bind the three light chains are shown in orange above the map. A region important for intermediate chain dimerization (Dimer; light blue) is also indicated. C, Identification of IC-1 phosphorylation in adult brain by CAD mass spectrometry. CAD MS/MS analysis of phosphorylated IC-1 peptide ETEALLQSIGISPEPPLVPTPM ${ }^{\circ x}$ *PSSK from adult rat brain shows the C-terminal SP serine as the phosphorylated residue. The predicted b-and y-type fragment ions are provided above and below the IC peptide amino acid sequence, respectively. Observed fragment ions are labeled within the spectrum and are underlined to indicate they were observed. The $M^{0 x}$ label indicates the presence of oxidized methionine as a result of the in-gel digestion process. The presence of $y 4, m / z 418$, shows that there is no phosphorylated residue on the last four amino acids, PSSK. The low abundancey ion, $y 5$ at $m / z 585$, lends evidence that the phosphorylated residue is at the following serine. The $y 7 \mathrm{at} / \mathrm{m} / \mathrm{z} 829$, validates that there has been an 80 Da mass shift. Therefore, we conclude that the serine residue in between $y 4$ and $7 \mathrm{has}$ been phosphorylated. The phosphorylated serine is indicated by an asterisk. 
Table 1. Quantitation of neuronal intermediate chain phosphorylation from mass spectra

\begin{tabular}{llllllr}
\hline Source & IC isoform & Peptide & Area (ion counts), phosphorylated & Area (ion counts), unphosphorylated & Total area & Percentage phosphorylation \\
\hline Embryonic neuron & 2B/2C & EAEALLQSMGLTTDSPIVPPPMS*PSSK & $6.53 \mathrm{E}+06$ & $6.02 \mathrm{E}+07$ & $6.67 \mathrm{E}+07$ & $9.8 \%$ \\
Embryonic neuron & BB/1C & ETEALLSIGISPEPPLVPTPMS*PSSK & $5.89 \mathrm{E}+07$ & $4.03 \mathrm{E}+07$ & $9.92 \mathrm{E}+07$ & $59.4 \%$ \\
Adult brain & B $/ 1 C$ & ETEALLQSIGISPEPPLVPTPMS*PSSK & $1.46 \mathrm{E}+07$ & $6.12 \mathrm{E}+07$ & $7.58 \mathrm{E}+07$ & $19.3 \%$ \\
\hline
\end{tabular}

Cytoplasmic dynein from the indicated sources was purified by immunoaffinity and the ICs resolved by SDS-PAGE. The IC bands were treated with trypsin and resulting peptides analyzed by mass spectrometry as described in Materials and Methods. The phosphorylated and unphosphorylated ion counts for the indicated peptides were calculated and converted to percentage of phosphorylation.

ing IC-2C (200-300 mm imidazole) were pooled and applied to a Q2 anion exchange column (Bio-Rad) and eluted with a linear gradient of $0-450 \mathrm{~mm} \mathrm{NaCl}$. Fractions containing IC-2C were pooled, frozen as aliquots in liquid nitrogen, and stored at $-80^{\circ} \mathrm{C}$. Yield was $\sim 0.5-1 \mathrm{mg}$ per $3 \mathrm{~L}$ culture, of which $\sim 50-75 \%$ was full-length IC-2C protein. In vitro phosphorylation reactions were performed essentially as described previously for MEK substrates (Slack-Davis et al., 2003; Eblen et al., 2004). Briefly, $450 \mathrm{ng}$ of recombinant IC-2C was incubated with or without recombinant ERK1 (MBL International) in the presence of $25 \mathrm{~mm}$ HEPES-NaOH, $10 \mathrm{~mm}$ magnesium chloride, $1 \mathrm{~mm}$ ATP, and $1 \mathrm{~mm}$ DTT for the indicated times at $30^{\circ} \mathrm{C}$.

\section{Reagents}

Antibodies. Rabbit polyclonal antibodies were prepared by Biomatik using peptide antigens, the peptide EAGSQDDLGPLTR for the $\alpha$-IC-1specific antibody, and the phosphopeptide TTDSPIVPPPMS ${ }^{\star}$ PSSKSVST PSE for the phospho-specific antibody, $\alpha$-pS-IC (the asterisk indicates the phosphorylated serine). Both antibodies were affinity purified using their antigenic peptide, except that for the phospho-specific antibody, antibodies that reacted with the unphosphorylated peptide were first removed by affinity chromatography with the unphosphorylated peptide. Other antibodies used were as follows: $\alpha$-pan IC, 74.1, a monoclonal pan anti-intermediate chain (Dillman and Pfister, 1994; Pfister et al., 1996b); $\alpha$-IC-2, polyclonal anti-intermediate chain 2 isoform (Vaughan and Vallee, 1995; Pfister et al., 1996a,b); DF18, a polyclonal pan Trk (gift from R. Segal, Harvard Medical School, Boston, MA); $\alpha$-pan Trk, B3 (Santa Cruz Biotechnology) (Bronfman et al., 2003; Arévalo et al., 2006); $\alpha$-Tu, Tu27, monoclonal anti-tubulin (Lee et al., 1990a,b) (gift from T. Frankfurter, University of Virginia, Charlottesville, VA); $\alpha$-syn, SY38, anti-synaptophysin, (Millipore) (Wiedenmann and Franke, 1985); function-blocking anti-BDNF (Millipore/ThermoFisher; catalog \#AB1513P); $\alpha$-pERK1/2 (Cell Signaling Technology; catalog \#9101); $\alpha$-Rab7 (gift from A. Wandinger-Ness, University of New Mexico, Albuquerque, NM) (Feng et al., 1995); $\alpha$-rab5 (BD Transduction Laboratories; catalog \#610281); and 9E10, anti-myc (University of Virginia Lymphocyte Culture Center).

Plasmids. IC-2C-mRFP, IC-1B-mRFP, TrkB-mRFP, TrkB-GFP, and constitutively active MEK1 S218D and S222D were described previously (Catling et al., 1995; Watson et al., 1999; Ha et al., 2008). TrkA in pLPLNCX (Clary and Reichardt, 1994) was a gift from Dr. L. Reichardt, University of California, San Francisco, CA. The TrkA-GFP plasmid was created by using PCR to add Xho1 and EcoR1 restriction sites for insertion into the eGFP vector (Clontech). Rab7-GFP (green lantern) (Guignot et al., 2004) was a gift from Dr. J. Casanova, University of Virginia, Charlottesville, VA. Mito-GFP was a gift from Dr. P. Hollenebeck, Purdue University, West Lafayette, IN. Point mutations of wildtype IC-2C and IC-1B to make phosphomimic, serine to aspartic acid $(\mathrm{S} / \mathrm{D})$, and dephosphomimic serine to alanine (S/A), mutants were engineered using the QuikChange II Site-Directed Mutagenesis Kit from Stratagene (Agilent Technologies), and the resulting PCR products were transformed in XL1-Blue supercompetent cells and sequenced to confirm the mutation. For IC-2C mutants, S81A was generated using the PCR primer GTC CCT CCT CCC ATG GCT CCA TCC TCC, and S81D was generated using GTC CCT CCT CCC ATG GAT CCA TCC TCC. For IC-1B mutants, S80A used G TGC CAA CCC CTA TGG CTC CCT CTT CGA AAT, and S80D used G TGCC AA CCC CTA TGG ATC CCT CTT CGA AAT.

siRNA RNA oligonucleotides were as follows: IC-2 experimental, GACT GGGTTTTAATACAGGAAGCAAA; IC-2 control, GACGGTTATTACAG AAGGACGTAAA; IC-1 experimental, AGTACATGTAAGCACAAATTCA
ACC and CCAAGCTCAGGAGAGAGGAAGTGAT; IC-1 control, GGTT TAAGTGTATTCGTACTGTACT and CCAACTCGAGGGAGAGAAGTG AGAT.

\section{Live cell imaging}

Coverslips with differentiated PC12 cells or primary hippocampal neurons were placed with culture medium in a custom made temperature control chamber at $37^{\circ} \mathrm{C}$ (Brook Industries) and imaged with an Olympus IX81 microscope equipped with a $94 \%$ neutral density filter and external exciter and emission filter wheels and internal dichroic filters (matched sets for GFP and mRFP from Chroma). The shutters, filter wheels, and camera were coordinated by MetaMorph7 (Photometrics). For kinetic analyses, single-color time-lapse illumination was used, and movies of puncta in living axons were collected for $25 \mathrm{~s}$ with a $100 \times$ lens (numerical aperture, 1.4) using a QuantEM camera (Photometrics) with no binning. Exposure times were $100 \mathrm{~ms}$ every $0.5 \mathrm{~s}$. Motile fluorescent dynein puncta were spots with two to three bright pixels. Kinetic analyses, including discrete interval movement velocities between each pair of movie frames, and excursive movements were calculated as described previously (Ha et al., 2008). One pixel equaled $0.17 \mu \mathrm{m}$. The smallest detectable velocity was $0.3 \mu \mathrm{m} / \mathrm{s}$.

\section{Colocalization}

To determine whether puncta of two fluorescently tagged proteins colocalized, fixed material was not used because it was observed that the smaller dynein puncta (one to two pixels) were often lost during the fixation. Movies of puncta in living axons were collected as above, except that a DualView (Photometrics) was used to simultaneously project the light emitted from the red and green fluorescent proteins on to different sides of the camera chip. Exposure times were $500 \mathrm{~ms}$ in streaming mode. The images from each side of the chip were aligned and superimposed with the Splitview analytic module (MetaMorph7), with manual verification of the alignment relative to either the fluorescent axon or a separate DIC image of the axon. Individual puncta were manually identified in each color channel of the combined image. Colocalization of the puncta was determined by sequentially turning off the display of one color at a time for every puncta. Partially overlapping puncta were not counted as colocalized. Adjacent movie frames were examined for verification if necessary. This method compensated for those axons or neurites with high uniform background of one of the colors and for the range of puncta intensities observed for both the dynein and the cargo (see Figs. $6,7)$. Individual movie frames were cropped and scaled in MetaMorph7; image Tiffs were arranged for presentation with Photoshop7 (Adobe), using the Auto Levels, Levels, Brightness, Contrast, or Curves functions, and labeled with Illustrator CS (Adobe).

To image dynein in axons of hippocampal or cortical neurons with the expression of endogenous IC reduced by siRNA (transfected at time of plating), the neurons plated on coverslips were transfected by calcium phosphate with fluorescent protein plasmids on DIV 3 and imaged on DIV 4. To analyze dynein in neurites of differentiated PC1 2 cells, with the expression of endogenous IC reduced by siRNA, the cells were transfected at time of plating and imaged $4 \mathrm{~d}$ after transfection. To image Rab7-GFP movement in UO126-treated hippocampal neurons, the transfected cells on coverslips were placed in fresh growth medium and incubated with UO126 or vehicle control for $30 \mathrm{~min}$ before assembly of the imaging chamber; coverslips were then imaged for $60 \mathrm{~min}$. To image TrkB-GFP movement in UO126-treated hippocampal neurons, the transfected cells on coverslips were placed in fresh growth medium and incubated with UO126 or BDNF control for 30 min before assembly of the imaging chamber; coverslips were then imaged for $60 \mathrm{~min}$. 

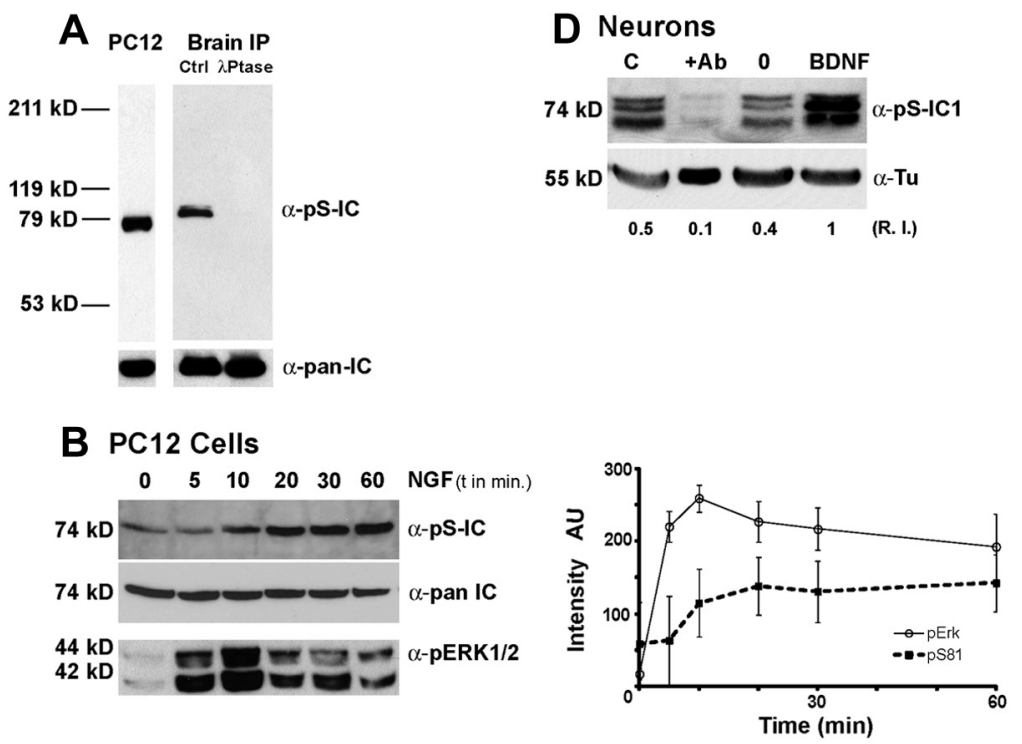

C Neurons
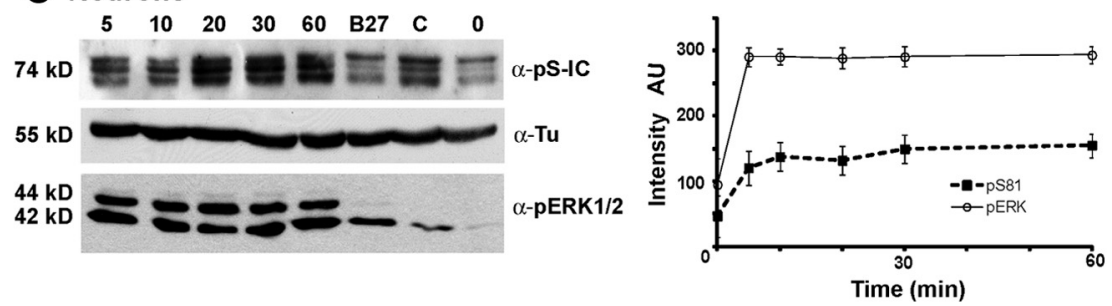

Figure 2. Neurotrophin stimulation of cytoplasmic dynein IC phosphorylation. $A$, Characterization of $\alpha$-pS-IC, an antibody to the PPMS*PSSK phosphorylation site. Top left lane, Blot of a PC12 cell lysate probed with the phospho-site-specific antibody $(\alpha-\mathrm{pS}-\mathrm{IC})$. A band corresponding to the IC-2 isoforms was detected by the antibody in lysate. Right lanes, Brain immunoprecipitate (IP). Cytoplasmic dynein was immunoprecipitated from a rat brain lysate with 74.1, a pan IC antibody ( $\alpha$-pan-IC), which reacts with all intermediate chain isoforms. The IP was divided into two equal fractions, and half was treated with lambda phosphatase ( $\lambda$ Ptase) and the other with buffer as a control (Ctrl). The samples were analyzed by SDS-PAGE and Western blotting. The phospho-specific antibody detects at least two intermediate chain bands in the control sample, but none in the phosphatasetreated sample, demonstrating that the antibody is specific for phosphorylated intermediate chains. Molecular weight markers are indicated on the left of the lane. Bottom, Portions of identical gels probed with the pan-IC antibody, showing that IC is present in all three lanes. $\boldsymbol{B}$, Time-dependent stimulation of cytoplasmic dynein IC phosphorylation by the neurotrophin NGF in PC12 cells. PC12 cells were incubated with NGF for the indicated times (in minutes). Left, Blots of cell lysates were probed with the antibodies indicated on the right, $\alpha$-pS-IC, $\alpha$-pan-IC as a loading control, and $\alpha$-pERK1/2, an antibody to the ERK1/2 kinases activated by phosphorylation. Right, The intensities of the bands were quantified with MetaMorph (in arbitrary units). The $\alpha$-pS-IC and $\alpha$-pERK1/2 intensities from three experiments were averaged, and the means and SEM are graphed with time after NGF addition. After a short lag, an average 2.3-fold increase in IC phosphorylation was observed within 20 min of the addition of NGF to the cells, and it remained constant for the duration of the experiment. ERK1/2 was maximally activated within 5-10 min of the addition of NGF, but the level of ERK1/2 activation deceased after $10 \mathrm{~min}$. Dashed line, pS-IC; solid line, p-ERK1/2. C, Time-dependent stimulation of neuronal dynein IC phosphorylation by the neurotrophin BDNF. Left, Blots of lysates of cortical neurons probed with $\alpha$-pS-IC, $\alpha$-Tu, tubulin antibody as a loading control, and $\alpha$-pERK1/2. C, Control cells grown under standard culture conditions; 0 , cells grown in neurotrophin depleted medium, as described in Materials and Methods; B27, cells to which the B27 supplement was added to neurotrophin depleted medium (for $60 \mathrm{~min}$ ). The numbers above the other lanes are the times in minutes after the addition of BDNF to cells in neurotrophin-depleted medium. The phospho-specific antibody reacts with three to four phosphorylated IC bands present in the neuron lysates (the resolution of the fastest migrating band varies from $1-2$ bands with changes in gel conditions). Right, The intensities of the bands were quantified with MetaMorph in arbitrary units. The quantified PS-IC and pERK1/2 intensities from five experiments were averaged, and the means and SEM are graphed with time after addition of BDNF. An increase in IC phosphorylation was observed within $5 \mathrm{~min}$ of the addition of BDNF to the cells, and it reached maximum (2.9-fold) within $10 \mathrm{~min}$. Maximum ERK1/2 activation was observed within $5 \mathrm{~min}$ of the addition of BDNF. The extent of ERK1/2 activation remained constant for the duration of the experiment $(60 \mathrm{~min})$. Dashed line, $\mathrm{PS}-\mathrm{IC}$; solid line, $\mathrm{p}$-ERK1/2. D, A function blocking antibody to BDNF significantly reduces phosphorylation of neuronal ICs. Blots of neuron cultures grown under different conditions are shown for control cells grown under standard culture conditions $(C)$, cells depleted of neurotrophin by medium replacement $(0)$, cells depleted of neurotrophin by medium replacement and the addition of a function blocking antibody to BDNF $(+\mathrm{Ab})$, and cells grown in medium depleted of neurotrophin then incubated with BDNF for $20 \mathrm{~min}$ (BDNF). The blot was probed with $\alpha$-pS-IC and $\alpha$-Tu as a loading control. R.I., Relative intensity. The intensities of the phospho-IC bands in the lanes were measured with MetaMorph and quantified relative to the level of BDNF-treated cells to demonstrate the effects of the different growth conditions relative to the level of the neurotrophin-stimulated IC phosphorylation in cells that were depleted of neurotrophin.
Survival assay

Sympathetic rat neurons were isolated from postnatal day 0 (P0)-P2 rat pups (Harlan) as described previously (Zareen and Greene, 2009). The neurons were cotransfected with either IC-1 siRNA scrambled control and mRFP (control), or cotransfected with IC-1 siRNA and either IC-1B-mRFP-WT or IC-1B S80AmRFP by Lonza nucleofection using the manufacturer's instructions for the rat neuron high-viability program. The neurons were plated in 96-well dishes coated with poly-L-lysine and laminin and grown in DMEM supplemented with $10 \% \mathrm{FBS}$, penicillin/streptomycin $(1 \mathrm{U} / \mathrm{ml})$, and $50 \mathrm{ng} / \mathrm{ml}$ of NGF. Glial contamination was removed from cultures by adding $5 \mu \mathrm{M}$ cytosine arabinofuranoside on DIV 1. On DIV 3, cells were washed three times with DMEM and placed in medium without NGF (in the presence of antiNGF) or $20 \mathrm{ng} / \mathrm{ml} \mathrm{NGF}$ for $36 \mathrm{~h}$. Cells were fixed with $4 \%$ paraformaldehyde at room temperature for 15 min and then stained with Hoechst 33258 $(1 \mu \mathrm{g} / \mathrm{ml}$; Invitrogen) at room temperature for 5 min. Images of Hoechst staining were acquired and blinded for unbiased quantification. Dead versus live neurons were scored as described previously (Deckwerth and Johnson, 1993). The survival of control neurons treated with $20 \mathrm{ng} / \mathrm{ml}$ NGF was set to 1 , and all other conditions are relative to this.

Mass spectrometry analysis of PC12 cell dynein intermediate chains

Dynein was immunoprecipitated from control or NGF-treated PC12 cells $(t=1 \mathrm{~h})$ and the subunits separated by SDS-PAGE and visualized by staining with Coomassie blue. Protein gel bands were excised and digested as described previously (Zhang et al., 2009). The resulting peptides were analyzed by liquid chromatography-MS/MS using an Eksigent HPLC (AB Sciex) coupled to a QSTAR Elite mass spectrometer (AB Sciex).

Mass spectrometry analysis of embryonic neuron and adult brain dynein

intermediate chains

Dynein was immunoprecipitated from starved or BDNF-treated ( $t=20 \mathrm{~min}$ ) embryonic cortical neurons and adult rat brain, and the subunits were separated by SDS-PAGE and identified by staining with Coomassie blue. Gel bands were excised, destained with 50:50 ethanol/0.1\% acetic acid, and subjected to in-gel trypsin digestion as reported previously (Shevchenko et al., 1996). After extraction of in-gel digest peptides, the sample was dried down via SpeedVac and reconstituted in $20 \mu \mathrm{l}$ of $0.1 \%$ acetic acid. For each sample, an aliquot of $5 \mu \mathrm{l}$ was loaded onto an irregular C18 (5-20 $\mu \mathrm{m})$ reverse-phase precolumn [360 $\mu$ m outer diameter (o.d.), $75 \mu \mathrm{m}$ inner diameter (i.d.); Polymicro Technologies] and rinsed with $0.1 \%$ acetic acid to remove any salts. For sample analysis by mass spectrometry, the precolumn was Teflon-sleeve connected to an analytical reverse-phase HPLC column (360 $\mu \mathrm{m}$ o.d., $50 \mu \mathrm{m}$ i.d.; Polymicro Technologies) packed with $7 \mathrm{~cm}$ regular C18 beads $(5 \mu \mathrm{m}$; ODS-AQ; YMC) with a $5 \mu \mathrm{m}$ emitter tip. Each sample was then analyzed by on-line nanoflow RP-HPLC 
A

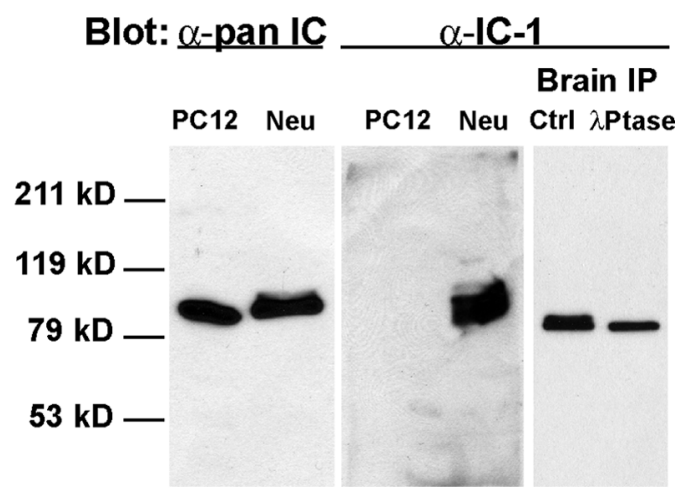

B

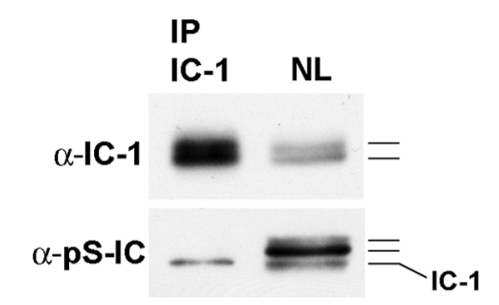

C

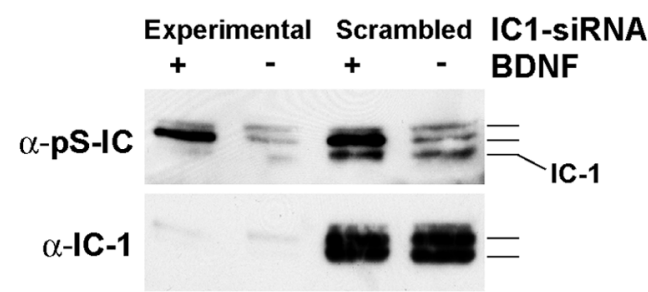

D

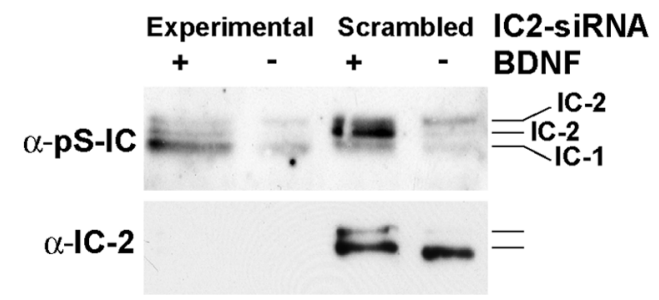

Figure 3. Identification of neuronal phospho-IC-1 and phospho-IC-2 by siRNA and immunoprecipitation. $A$, Characterization of $\alpha-\mathrm{IC}-1$, an antibody specific for the IC- 1 intermediate chain isoforms. The first two panels are blots of PC12 cells and embryonic cortical neuron (Neu) lysates. The first panel was probed with $\alpha$-pan IC and shows that comparable amounts of cytoplasmic dynein intermediate chains were loaded in the PC12 cell and neuron lanes. The second panel is an identical blot probed with the IC-1-specific antibody $(\alpha-\mathrm{IC}-1)$, and no intermediate chains were detected in the PC12 cell lane. PC12 cells contain only dynein with the IC-2 isoforms. This demonstrates that the antibody does not cross-react with IC-2 isoforms. Neurons express IC -1 and IC 2 isoforms, and the antibody clearly detects the IC -1 intermediate chains in the neuronal lane. In the third panel (Brain IP), cytoplasmic dynein was immunoprecipitated from a rat brain lysate with the pan IC antibody ( $\alpha$-pan-IC). The IP was divided into two equal fractions, and half was treated with lambda phosphatase ( $\lambda$ Ptase) and the other with buffer as a control (Ctrl). The samples were analyzed by SDS-PAGE and Western blotting. The IC-1-specific antibody detected two intermediate chain bands in the control sample and one in the phosphatase-treated sample. The top band is likely to be the phosphorylated IC. Molecular weight markers are indicated on the left of the blot panels. $\boldsymbol{B}$, IC-1-specific immunoprecipitation. Cytoplasmic dynein containing only the IC -1 isoform was purified by immunoprecipitation with $\alpha-\mathrm{IC}-1$ from BDNF-stimulated cortical neurons. Identical blots of the immunoprecipitate (IP IC-1) and a cortical neuron lysate (NL) were probed with $\alpha-\mathrm{IC}-1$ and $\alpha$-pS-IC. Dashes on the
(Agilent 1100), gradient-eluted into a microelectrospray ionization source of an Orbitrap mass spectrometer (ThermoFisher Scientific) equipped with front-end ETD (electron transfer dissociation, an in-house design). Mass analyses were completed with one high-resolution $(60,000$ resolution at $400 \mathrm{~m} / z$ ) full MS scan followed by five each of CAD (collisionactivated dissociation) and ETD data-dependent $\mathrm{MS}^{2}$ scans. For ETD experiments, $\mathrm{MS}^{2}$ parameters were as follows: $30 \mathrm{~ms}$ reaction time, $3 \mathrm{~m} / \mathrm{z}$ precursor isolation window, charge state rejection "on " for +1 charge state precursors, $2 \times 10^{5}$ Fourier transform mass spectrometry full AGC target, $1 \times 10^{4}$ ion trap mass spectrometry AGC target, and $2 \times 10^{5}$ reagent target with azulene as the electron transfer reagent. Data were searched using the Open Mass Spectrometry Search Algorithm (OMSSA) against a database of all dynein IC-74 isoforms. Search parameters allowed for a variable modification of oxidation at methionine residues; variable modification of phosphorylation at serine, threonine, and tyrosine; and specified trypsin cleavage at lysine and arginine (except before a proline group), with up to two missed cleavages allowed. Searches were performed with a precursor mass tolerance of $0.1 \mathrm{amu}$ and a fragment mass tolerance of $0.35 \mathrm{amu}$. Peptide sequence and OMSSA phosphorylation site assignments were validated manually from the raw MS/MS spectra.

\section{Results}

Identification of neurotrophin-sensitive dynein phosphorylation

The primary microtubule-based motor for retrograde axonal transport is cytoplasmic dynein, a large protein complex with six subunits. To investigate dynein interactions with signaling endosomes, we concentrated on one subunit, the intermediate chain, because of its central scaffold-like role in the dynein complex (Lo et al., 2006; Pfister et al., 2006). There are multiple IC isoforms in vertebrates, the product of two genes and alternative splicing. The IC-1B, IC-1C, IC-2B, and IC-2C isoforms are expressed in cultured neurons, while only IC-2C and IC-2B are expressed in PC12 cells (Pfister et al., 1996a,b; Crackower et al., 1999; Salata et al., 2001; Myers et al., 2007; Kuta et al., 2010). We have shown that the ICs define dynein complexes with different properties and functions in neurons (Dillman et al., 1996; Ha et al., 2008). We have also shown that the ICs are phosphorylated in neurons, optic nerves, and PC12 cells, and that differentiation of PC12 with NGF resulted in increased IC phosphorylation (Dillman and Pfister, 1994; Salata et al., 2001).

To determine the functional significance of the IC phosphorylation, we used mass spectrometry to identify the phosphory-

$\leftarrow$

right mark the positions of the bands. The $\alpha-\mathrm{IC}-1$ reacted with two bands in neuron lysates and in the $\alpha-\mathrm{IC}-1$ immunoprecipitate. Three bands that reacted with $\alpha$-pS-IC were resolved in the cortical neuronal lysates. One $\alpha$-pS-IC-reactive IC band was detected in the IC- 1 immunoprecipitate, and it corresponds to the fastest migrating band of the three observed in cortical neurons; that band is therefore identified as IC-1. C, IC-1 depletion with siRNA. Cortical neurons were transfected with siRNA oligonucleotides to the IC-1 UTR (Experimental) or scrambled control oligonucleotides (Scrambled). Transfected cells were then lysed on DIV 4, after neurotrophin depletion by medium exchange $(-)$ or with the addition of BDNF to depleted medium for $15 \min (+)$. The $\alpha-\mid \mathrm{IC}-1$ reacted with two bands in the control lanes, but there was substantial depletion $(90 \%)$ of the immunoreactivity in the experimental siRNA lanes. The $\alpha$-pS-IC reacted with three bands in the control lanes, but depletion of IC- 1 lead to a reduction in the amount of the fastest migrating band in the $\alpha$-pS-IC blot, in agreement with the IC-1 immunoprecipitation (Fig. 3B). D, IC-2 depletion with siRNA. Cortical neurons were transfected with a siRNA oligonucleotide to the IC-2 UTR (Experimental) or a scrambled control oligonucleotide (Scrambled). Transfected cells were then lysed on DIV 4 after neurotrophin depletion (-) or with the addition of BDNF to depleted medium for $15 \mathrm{~min}(+)$. The $\alpha$-IC-2 (an IC-2-specific antibody) reacts with two bands in the control lanes, but there is substantial depletion (80\%) of immunoreactivity in the experimental siRNA lanes. There may be band shifting in the presence of neurotrophin, perhaps the result of phosphorylation. Depletion of IC-2 resulted in a reduction in the immunoreactivity of the two slowest migrating bands in the $\alpha$-pS-IC blot, demonstrating that these two bands are IC- 2 isoforms. 

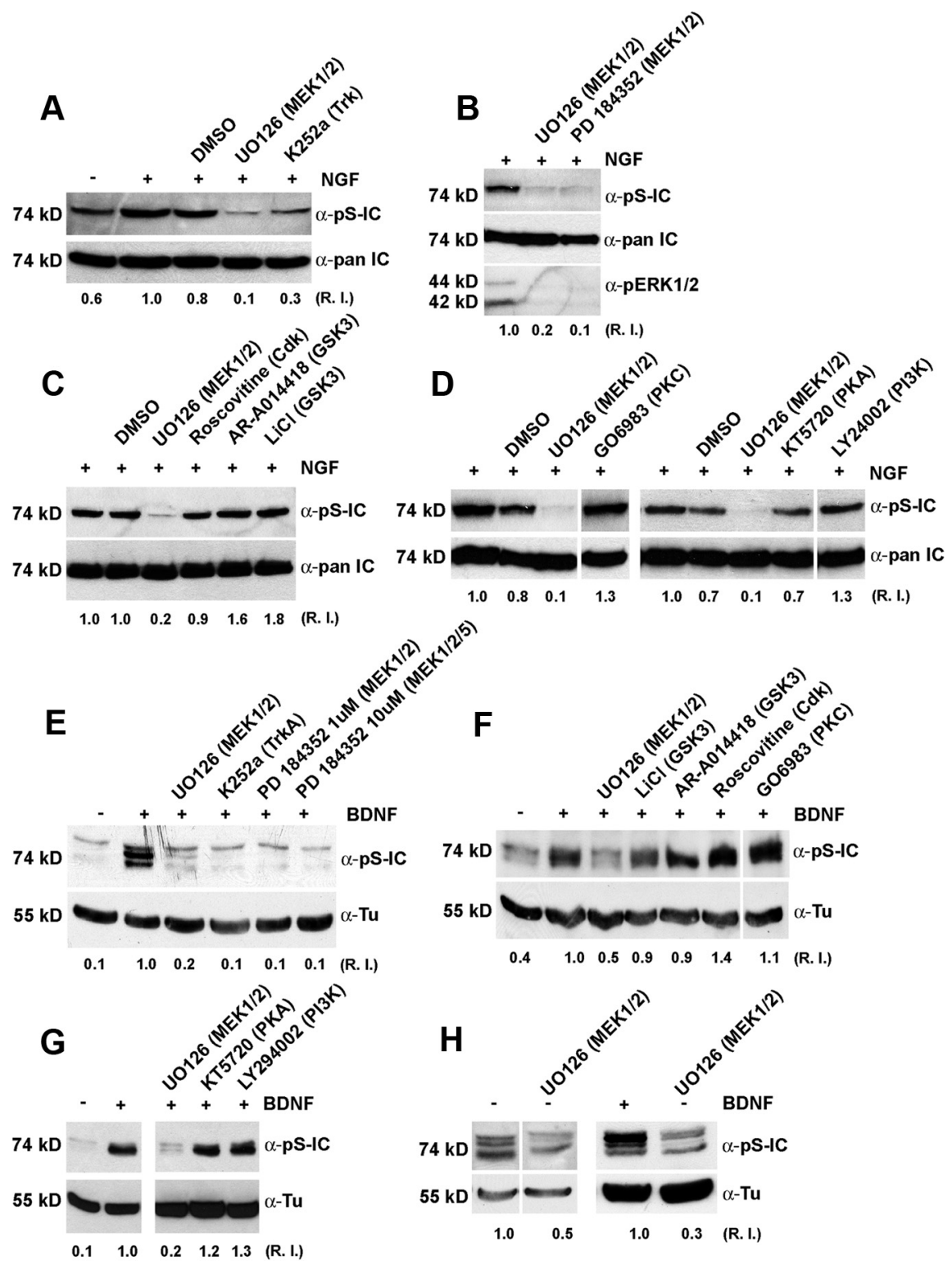

Figure 4. IC phosphorylation requires active Trk and ERK1/2. The indicated kinase inhibitors (both the inhibitor and the target kinase are listed for clarity) or vehicle control (DMSO) were added to the PC12 cells and embryonic neurons as indicated, and identical blots of cell lysates were probed with $\alpha$-pS-IC and $\alpha$-pan IC or $\alpha$-Tu as loading controls. The intensities of the IC bands were measured with MetaMorph and were quantified relative to neurotrophin-treated cells [relative intensity (R.I.)] to evaluate the efficacy of the inhibitors in reducing the level of the neurotrophin-stimulated IC phosphorylation. The level of inhibition produced by the MEK inhibitor, U0126, provides an additional calibration between the different experiments. $\boldsymbol{A}-\boldsymbol{D}, \mathrm{PC} 12$ cells. The inhibitors were added to the PC12 cell culture medium for 30 min before addition of NGF. The cells were lysed 30 min after addition of NGF. $A$, Addition of NGF increased the level of IC phosphorylation $\sim 1.7$ fold over control cells without NGF. Addition of the Trk kinase inhibitor, K252a, blocked the NGF induced stimulation of IC phosphorylation and reduced the IC phosphorylation level to below that of control cells. U0126, which blocks the activation of MEK and thus the activation of ERK1/2, also inhibited the neurotrophin stimulation of IC phosphorylation. $\boldsymbol{B}$, Two structurally unrelated MEK inhibitors U0126 and PD184352 blocked ERK1/2 activation ( $\alpha$-pERK1/2), and the NGF induced stimulation of IC phosphorylation ( $\alpha$-pS-IC). C, Inhibitors of cell cycle kinases (Cdk) and GSK3 did not block the NGF induced stimulation of phosphorylation. D, Inhibitors of PKC and PI3K, signaling pathways downstream of Trk, and PKA did not block the NGF stimulation of phosphorylation. $\boldsymbol{E}-\boldsymbol{H}$, Neurons. Cortical neurons were grown on dishes and depleted of growth factors. The inhibitors were added to the culture medium $30 \mathrm{~min}$ before addition of BDNF. The cells were lysed 15 min after addition of BDNF. $\boldsymbol{E}$, Inhibitors of the Trk kinase and the MEK ERK activator blocked the BDNF induced stimulation of IC phosphorylation. Two concentrations of PD 184352 were used to distinguish between ERK1/2 and ERK5. Inhibition of IC phosphorylation with the lower concentration identifies ERK1/2 as the inhibited kinase. $\boldsymbol{F}$, Inhibitors of cell cycle kinases (Cdk), GSK3, and PKC did not block the BDNF-induced stimulation of phosphorylation. $G$, Inhibition of PKA or $\mathrm{PI} 3 \mathrm{~K}$ did not block IC phosphorylation. $\boldsymbol{H}$, Cortical neurons were grown under regular culture conditions. Left, Blot showing a comparison of IC phosphorylation levels in control (untreated) cells to cells treated with U0126 for 30 min before lysis. Right, Blot comparing IC phosphorylation levels in cells treated with either BDNF or U0126 for 30 min before lysis. lated amino acid(s) of cytoplasmic dynein ICs isolated from neurons and PC12 cells. When the IC of dynein purified from PC12 cells was analyzed, a tryptic peptide, EAEALLQSMGLTTDSPIVPPPMS ${ }^{*}$ PS SK, was found to be phosphorylated (Fig. $1 A)$. MS/MS fragmentation of this peptide indicated that serine 81 was the site of phosphorylation (marked with an asterisk). Brief exposure of PC12 cells to NGF increased the MS signal intensity for this peptide threefold to fourfold relative to ICs from unstimulated cells. This peptide is found in the IC- $2 \mathrm{~B}$ and IC-2C isoforms. Both isoforms have the first alternative splice region excised. The peptide is located near the $\mathrm{N}$ terminus of the IC, and about two-thirds of it precedes the first alternative splicing region (Fig. $1 B$ ).

Neurons express both IC- 1 and IC-2 isoforms. We next used mass spectrometry to characterize IC-1 phosphorylation in dynein purified from adult rat brain. Wefound an IC-1 peptide, ETEALLQSMG LTTDSPIVPPPMS ${ }^{*}$ PSSK, that was phosphorylated (Fig. 1C). This IC-1 peptide corresponds to the IC-2 peptide described above. It is found in both the IC-1B and IC-1C isoforms, and the phosphorylated amino acid corresponds to S80 in IC$1 \mathrm{~B} / \mathrm{C}$ (marked with an asterisk) (Fig. $1 B, C)$. Phosphorylated IC-1 S80 and IC-2 S81 were also found in cultured embryonic cortical neurons. By comparing the signals from the phosphorylated and unphosphorylated peptides, we estimated that in the cultured neurons, $\sim 10 \%$ of the IC- 2 and $60 \%$ of the IC- 1 was phosphorylated, and in adult brain, $\sim 20 \%$ of the IC-1 was phosphorylated (Table 1). No peptide that could be assigned to IC-1A or IC-2A was detected by mass spectrometry of the brain or neuron IC samples, consistent with our previous observation that they are not expressed in cultured embryonic neurons, and their expression in brain is at low abundance (Pfister et al., 1996a,b; Kuta et al., 2010). These newly identified IC phosphorylation sites are conserved in vertebrates, but are not conserved in lower organisms.

To investigate the role of the IC phosphorylation in the recruitment of dynein to Trk-containing signaling endosomes, we prepared a phospho-specific antibody to the phosphorylation site on the two ICs. The antibody reacted with the dynein ICs in PC12 cell lysates (Fig. 2A). It also reacted with the ICs of dynein immunopurified from rat brain, and pretreatment of the dynein with lambda phosphatase removed the immunoreactivity. This characterization of the antibody demon- 
strated that it was specific for the phosphorylated forms of IC-1 and IC-2.

We then characterized the changes in IC phosphorylation levels in response to neurotrophin in PC12 cells and neurons. In PC12 cells, it was observed that after an initial lag, within 10-20 min, the IC phosphorylation level had increased 2.3-fold to its maximal level, and it remained relatively constant for at least 60 min (Fig. $2 B$ ). The effect of BDNF on the phosphorylation level of the ICs in cultured cortical neurons was also examined. BDNF is secreted by neurons and thus is found in conditioned culture medium (Altar and DiStefano, 1998; Chang et al., 2003; Deppmann et al., 2008). To determine whether cortical neuron IC phosphorylation was stimulated by BDNF, we first depleted the neurotrophins by replacing the conditioned medium as described in Materials and Methods. The phospho-specific IC antibody detected three to four IC bands in cortical neurons grown under normal culture conditions, and the depletion protocol reduced the level of phosphorylation (Fig. 2C). Within 5 min after the addition of BDNF to the depleted medium, there was an increase in the phosphorylation levels of the ICs, and by $10 \mathrm{~min}$ it had increased 2.9-fold to its maximal level. As was observed with PC12 cells, this increase in phosphorylation persisted for at least $60 \mathrm{~min}$. Interestingly, the growth factors present in the B27 neuron medium supplement, including insulin, induced only a 1.3fold stimulation of the IC phosphorylation (Fig. 2C). To determine whether the residual phospho-IC observed in cells depleted of neurotrophin might be due to BDNF secreted into the medium by the cells, we added a function blocking antibody to BDNF to the fresh medium. The presence of the antibody in the growth factor depleted medium lowered the amount of phosphoantibody staining (Fig. 2D). This further demonstrated that the level of IC phosphorylation is sensitive to the concentration of BDNF in the medium.

Cortical neurons express both IC-1 and IC-2 isoforms, and axonal TrkB signaling endosomes are transported by IC-1 dynein (Pfister et al., 1996a,b; Ha et al., 2008). Two approaches were used to determine whether IC-1 and/or IC-2 isoforms were phosphorylated in response to BDNF. First, we developed an IC-1-specific antibody (Fig. $3 A$ ) and used it to immunopurify dynein complexes containing exclusively IC-1 from rat brain. Two IC-1reactive bands were identified in the immunoprecipitate and in the cortical neuron lysates (Fig. 3B). Three phospho-IC-reactive bands were found in the lysates, and the phospho-specific antibody showed reactivity with one band in the IC-1 immunoprecipitate, a band that comigrated with the fastest migrating band in cortical neuron lysates (Fig. $3 B$ ). The identification of the fastest migrating band as IC-1 was confirmed by depleting cultured neurons of IC-1 with siRNA. When the experimental siRNA oligonucleotides were transfected into cultured neurons, they substantially reduced the expression of the two bands detected by the IC-1specific antibody. In the experimental IC-1 siRNA lanes, there were also markedly reduced amounts of the fastest migrating band detected by phospho-specific antibody, while comparable amounts of the two slower migrating bands were observed in the control and experimental lanes (Fig. 3C). These experiments demonstrate that the fastest migrating band detected by the phospho-specific antibody is an IC-1. The two slower migrating bands detected by the phospho-specific antibody were shown to have reduced levels after transfection with IC-2-specific siRNA, demonstrating that they are the product of IC-2 (Fig. 3D). Since all three of these bands show increased phospho-specific antibody reactivity after the addition of BDNF, there is increased phosphorylation of both IC-1 and IC-2 isoforms upon the addition of BDNF to the neuronal culture me-
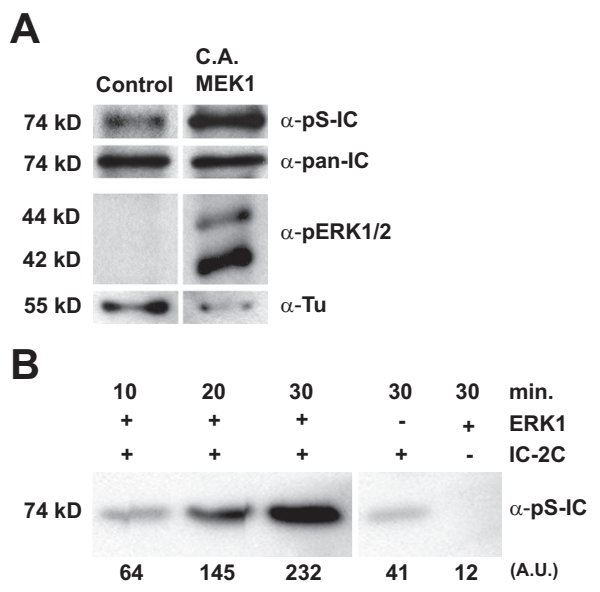

Figure 5. ERK phosphorylation of the cytoplasmic dynein IC. $\boldsymbol{A}$, Constitutively active MEK stimulates IC phosphorylation independent of NGF in PC12 cells. PC12 cells were cotransfected with myc-IC-2C and constitutively active MEK-HA (C.A. MEK1) or HA-vector (Control). The IC was immunoprecipitated from cell lysates with an antibody to myc. Blots of the immunoprecipitates were probed with $\alpha$-pS-IC and $\alpha$-pan-IC antibody as a loading control. Blots of the cell lysates were probed with $\alpha$-pERK1/2 and $\alpha$-Tu as a loading control. Cotransfection of IC-2C and C.A. MEK increased the amount of active ERK in the cell lysates and increased IC phosphorylation in the absence of NGF. $\boldsymbol{B}$, ERK1 phosphorylation of IC-2C in vitro is recognized by the PS-IC epitope. Recombinant IC -2 C was incubated with $(+)$ or without $(-)$ recombinant ERK1 and Mg2 + ATP for the indicated times in minutes. Blots were probed with $\alpha$-pS-IC. The intensities of the bands in were quantified with MetaMorph in arbitrary units. Incubation with ERK1 resulted in a timedependent increase in the amount of IC phosphorylation detected with the PS-IC-specific antibody.

dium. These data further demonstrate that the levels of IC-1 and IC-2 can be specifically depleted in cultured neurons with siRNA.

ERK1/2 and phosphorylation of the cytoplasmic dynein intermediate chain

We next characterized the effect of kinase inhibitors on the increased IC phosphorylation observed in response to the addition of neurotrophins. First, we showed that inhibition of the Trk kinases with K252a blocked the NGF and BDNF induced stimulation of dynein phosphorylation in PC12 cells and neurons (Fig. $4 A, E)$. This provided evidence that the IC kinase was either Trk or a downstream effector of the Trk kinases. The ScanSite algorithm (Obenauer et al., 2003) was used to search for motifs within the IC peptide sequences that were likely to be phosphorylated by specific protein kinases. The algorithm proposed ERK, cell cycle kinases, and GSK3 as kinases with the potential to phosphorylate the ICs on this site. In particular, the IC-1 S80 and IC-2 S81 amino acids fell within an excellent consensus sequence (PXSP) for phosphorylation by ERK (Songyang et al., 1996).

ERKs, members of the MAP kinase family, are a major downstream effector of the Trk kinase. We next inhibited the activation of ERK1/2 by using UO126 to block the activation of MEK. Since MEK must be activated to activate ERK, this compound blocks the activation of ERK (Fig. $4 B$ ). We found that this inhibitor prevented the stimulation of IC-2 phosphorylation by NGF in PC12 cells and the stimulation of IC- 1 and IC-2 phosphorylation by BDNF in neurons (Fig. $4 A, E$ ). In most experiments there was 5- to 10 -fold less IC phosphorylation when the inhibitor was present. Additional evidence for the involvement of ERK1/2 was obtained by the finding that PD 184352, which is structurally unrelated to UO126 and inhibits MEK1/2 activation in a different way (Davies et al., 2000; Bain et al., 2003), also blocked the neurotrophin-stimulated phosphorylation in PC12 cells and activation of ERK1/2 (Fig. 4B). ERK5 is the downstream effector of 


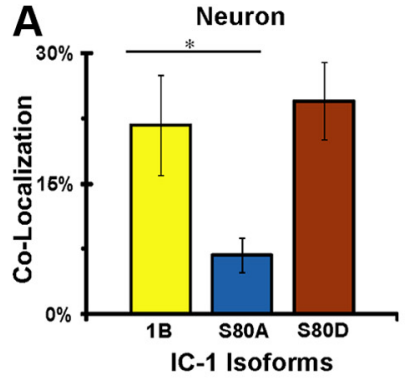

B
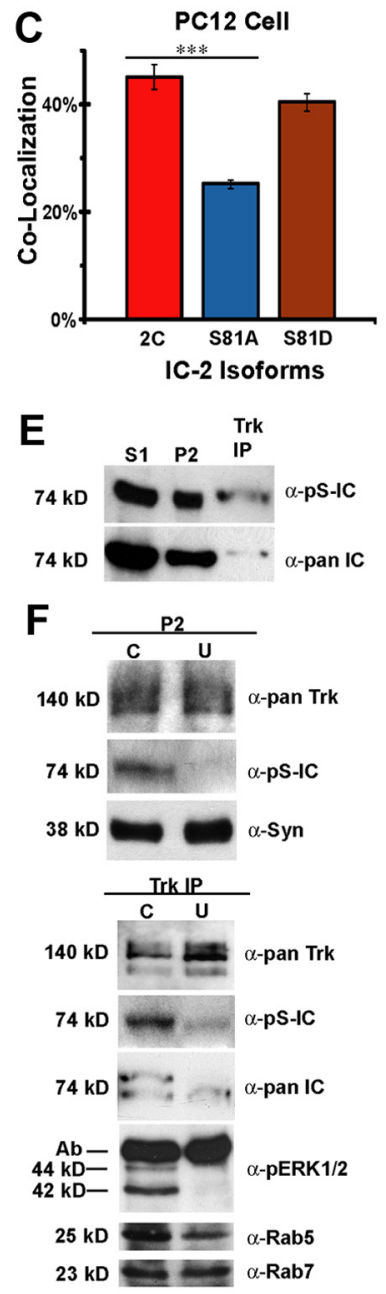

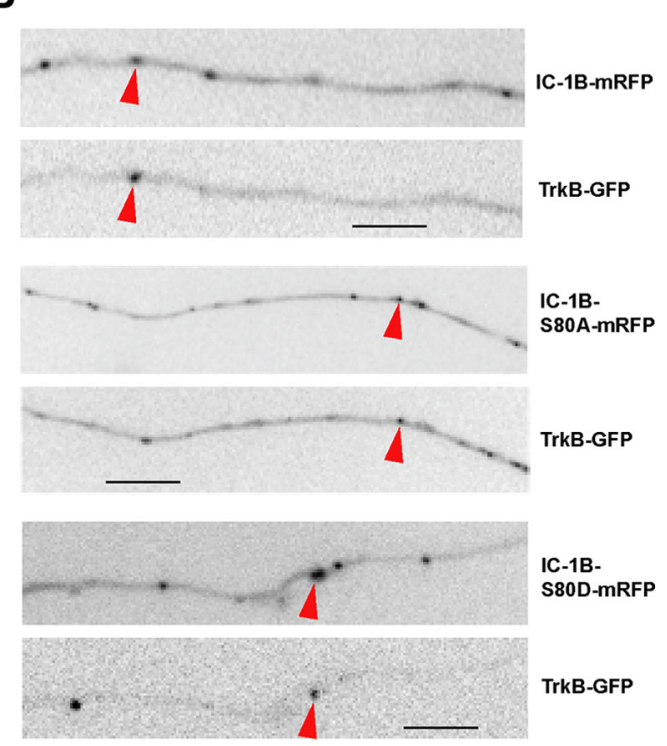

D
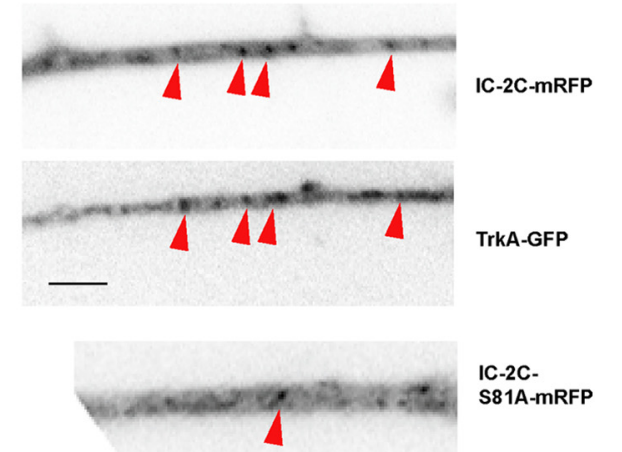

TrkA-GFP
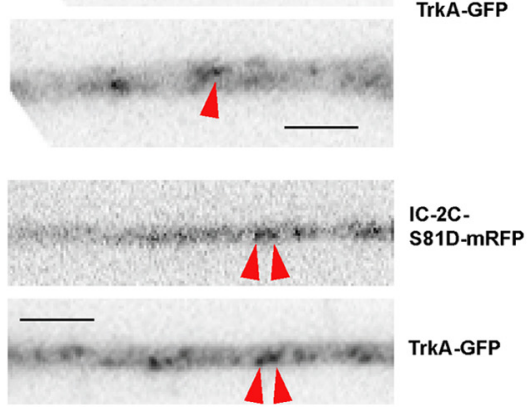

Figure 6. IC dephosphorylation reduces dynein binding to Trk-containing endosomes. $A$. The dephosphomimic IC-1B S80A mutation reduces the colocalization of dynein with TrkB in cultured neurons. Cultured embryonic hippocampal neurons depleted of IC-1 by siRNA were cotransfected with TrkB-GFP and either IC-1B-mRFP WT, dephosphomimic IC-1B S80A, or phosphomimic mutant IC-1B S80D. Axons of living cells were simultaneously imaged in the GFP and RFP channels with DualView, and the percentage of overlapping puncta was quantified. The dephosphomimic IC-1B S80A showed significantly less colocalization with TrkB than WT 1B ( ${ }^{*} p<0.02$, Student's t test). Numbers of puncta analyzed were 83 WT $1 B$ and 96 TrkB, 164 S80A and 83 TrkB, and 66 S80D and 71 TrkB. The difference between WT $1 B$ and the IC-1B S80D phosphomimic mutant was not significant. $\boldsymbol{B}$, Imaging the colocalization of IC-1B with TrkB in axons of cultured hippocampal neurons. The three pairs of panels are portions of single DualView frames from the movies of axons prepared as described in $\boldsymbol{A}$ with the TrkB and IC-1B signals aligned and the puncta displayed in reverse contrast. The bottom panel of each pair is the TrkB-GFP portion of the frame, and the top panel of each pair is the IC-1B-GFP (WT or mutant) portion as indicated. Red arrowheads identify puncta that colocalize. Puncta that showed only partial overlap or that did not colocalize in all frames are not identified. In these examples, $25 \%$ of the IC-1B WT dynein colocalized with TrkB, $12.5 \%$ of the IC-1B S80A colocalized with TrkB, and 25\% of the IC-1B S80D colocalized with TrkB. C, The dephosphomimic mutation IC-2C S81A has reduced colocalization with TrkA in living PC12 cells. PC12 cells were depleted of endogenous IC-2 by siRNA and cotransfected with TrkA-GFP, and either IC-2C-mRFP WT, dephosphomimic IC-2C S81A, or phosphomimic mutant IC-2C S81D. Neurites of living cells were simultaneously imaged in the GFP and RFP channels with DualView, and the percentage of colocalizing puncta was quantified. The dephosphomimic IC-2C S81A showed significantly less colocalization with TrkA than WT $\left({ }^{* * *} p<0.001\right.$, Student's $t$ test). Numbers of puncta analyzed were 187 WT 2 C and 311 TrkA, 200 S81A and 327 TrkA, and 342 S81D
TrkB that promotes neuronal survival (Watson et al., 2001; Valdez et al., 2005). To distinguish between ERK1/2 and ERK5, we used two different concentrations of PD 184352. While high concentrations of the drug inhibit ERK1/2 and ERK5, ERK1 and ERK2 are selectively inhibited by lower concentrations (Bain et al., 2007). We found that the lower concentration of PD 184352 inhibited the BDNF-stimulated phosphorylation of both IC- 1 and IC-2 in neurons and IC-2 in $\mathrm{PC} 12$ cells, providing evidence that ERK1/2 is the more likely IC kinase (Fig. $4 B, E)$.

Inhibitors of GSK3 and the cell cycle kinases, the alternative candidate IC ki-

and 444 TrkA. The difference between the WT IC-2C and the S81D mutant was not significant. D, Imaging the colocalization of IC-2C with TrkA in PC12 cell neurites. The three pairs of panels are portions of single frames from the DualView movies of PC12 cell neurites described in $C$ with the TrkA and IC-2C signals aligned and the puncta displayed in reverse contrast. The bottom panel of each pair is the TrkA-GFP portion of the frame, and the top panel of each pair is the IC-2C-GFP (WT or mutant) portion as indicated. Red arrowheads identify puncta that colocalize. Puncta that only showed partial overlap or that did not colocalize in all frames are not identified. In these examples, 44\% of IC-12C WT colocalized with TrkA, $12.5 \%$ of IC-2CB S81A colocalized with TrkA, and 40\% of IC-1B S81D colocalized with TrkA. E, Phosphorylated IC is enriched on immunoaffinity-purified Trk-containing organelles. PC12 cells were briefly stimulated with NGF to induce formation of signaling endosomes. The cells were homogenized, and the initial cytosol (S1) and crude total membrane factions (P2) were obtained by centrifugation. Trk-containing membranes were isolated from the P2 by immunoaffinity (Trk IP), and the blots were probed with $\alpha$-pS-IC and $\alpha$-pan-IC. When the $\mathrm{pS}-\mathrm{IC}$ and pan-IC antibody signals in the S1, P2, and Trk-IP lanes were quantified, a 2.4-fold enrichment of $\mathrm{pS}$ - IC associated with the Trk organelles relative to the $S 1$ and $P 2$ was observed. $F$, The MEK kinase inhibitor U0126 reduces the amount of dynein associated with Trk-containing organelles. Top, Blots of equal volumes of crude total membrane fractions (P2) prepared from NGF-stimulated control $(\boldsymbol{C})$ and U0126 $(\boldsymbol{U})$ pretreated $\mathrm{PC} 12$ cells were probed with $\alpha-\mathrm{pS}-\mathrm{IC}$, and antibodies to the membrane proteins synaptophysin ( $\alpha$-Syn) and Trk ( $\alpha$-pan Trk) were used as loading controls. Treatment with U0126 reduced the amount of phospho-IC in the crude total membrane pellets by $90 \%$. Bottom, Blots of immunoaffinity-purified Trkcontaining organelles prepared from the P2s from control (C) or U0126 (U) pretreated cells were probed with pan-Trk, pS-IC, pan-IC, pERK1/2, Rab5, and Rab7 antibodies. Both immunoprecipitates contain Trk, Rab7, and Rab5. The presence of both Rab5 and Rab7 suggests that the purified signaling endosomes are from different stages of the endosome cycle. Activated ERK1/2 was present in the immunoprecipitate from control cell membranes, but not the immunoprecipitate from U0126-treated cells. The position of the antibody used in the immunoprecipitation is indicated by Ab on the pERK $1 / 2$ blot. U0126 treatment of $\mathrm{PC} 12$ cells before the addition of NGF reduced the amount of the dynein ICs that copurified with Trkcontaining organelles. Scale bars: $5 \mu \mathrm{m}$. Error bars indicate SEM. 
nases identified by ScanSite, did not block the neurotrophinstimulated IC phosphorylation in PC12 cells or neurons (Fig. $4 C, F)$. Inhibitors of PI3K and PKC, components of two other major Trk-stimulated signaling pathways, also did not inhibit neurotrophin-stimulated IC phosphorylation in the two model cell systems (Fig. 4D,F,G). In PC12 cells, the presence of the GSK3 inhibitors resulted in a slight stimulation of the IC phosphorylation, which was not observed in neurons. The Trk inhibitor K252a is known to inhibit PKA. Therefore, to confirm that PKA did not contribute to IC phosphorylation, we used KT5720, a PKA inhibitor that does not inhibit Trk kinase, and found that it did not block the neurotrophin-stimulated IC phosphorylation increase in PC12 cells or neurons (Fig. $4 D, G$ ).

We compared the time course of ERK1/2 activation in response to neurotrophin stimulation in PC12 cells and neurons to that of the IC phosphorylation and observed subtle differences between the two systems (Fig. $2 B, C$ ). There was a brief lag in IC phosphorylation relative to ERK1/2 activation in PC12 cells that was not observed in neurons. Also, the level of ERK1/2 activation began to decrease gradually after $10 \mathrm{~min}$ in PC12 cells but not in neurons. In both cell systems, IC phosphorylation level was relatively stable for 60 min once the maximal level was reached.

To further demonstrate the role of ERK1/2 in the phosphorylation of the IC, constitutively active MEK1 was transfected into PC12 cells. It was observed that constitutively active MEK was sufficient to induce ERK activation and IC phosphorylation in the absence of NGF (Fig. 5A). When the intensities of the pS-IC bands were quantified, a 2.2-fold increase was found in the phosphorylation of the IC from the constitutively activated MEK transfected cells relative to the control transfected cells. We next sought to determine whether ERK1/2 phosphorylation of the IC was sufficient to generate the epitope recognized by the phosphosite-specific antibody in vitro. ERK1 and IC-2C were purified from bacteria and combined in the presence of $\mathrm{Mg}^{+2}$ ATP. As assayed by the phospho-site-specific antibody, ERK1 phosphorylated IC-2 S81 in a time-dependent manner (Fig. 5B). These results support the evidence that ERK1/2 is responsible for the phosphorylation of the ICs.

Intermediate chain phosphorylation modulates dynein association with Trk-containing organelles

We demonstrated previously that IC-2C associated with TrkA in PC12 cells, whereas in hippocampal neurons, which express four IC isoforms, IC-1B colocalizes with TrkB-containing signaling endosomes to a greater extent than IC-2C (Ha et al., 2008). To examine the functional significance of the observed neurotrophin-stimulated IC phosphorylation, we analyzed the distributions of the intermediate chains and Trks in living cells by expressing fluorescently tagged Trks and ICs in hippocampal neurons and PC12 cells. After depleting the cells of the relevant endogenous IC isoform with siRNA (Fig. 3) (Ha et al., 2008), we compared the levels of colocalization of Trk with the S/D phosphomimic and S/A dephosphomimic mutants relative to WT IC. In cultured hippocampal neurons, there was no significant difference in the extent of colocalization of TrkB puncta with WT IC-1B and IC-1B S80D phosphomimic mutation puncta (Fig. 6A,B). However, there was a significant decrease in the level of colocalization of the S80A dephosphomimic mutant with TrkB. The decreased Trk colocalization observed with IC-1B S80A was not due to relative differences in protein expression, as there was no difference in the densities of fluorescent dynein puncta in axons between the three IC-1B proteins (Table 2). In PC12 cell neurites, more than $40 \%$ of the IC-2C colocalized with TrkA (Fig. $6 C, D$ ). It was also observed that the IC-2C S81A dephosphomimic mutant
Table 2. Comparison of the density and retrograde interval velocities of WT IC-1B and the IC-1B 580 phosphomimic and dephosphomimic mutants

\begin{tabular}{llll}
\hline Intermediate chain isoform & WT & S80A & S80D \\
\hline $\begin{array}{l}\text { Mean dynein density (puncta/ } \\
\mu \text { m of axon length) }( \pm \text { SEM) }\end{array}$ & $0.090(0.007)$ & $0.099(0.007)$ & $0.096(0.007)$ \\
Mean interval retrograde & $0.84(0.02)$ & $0.71(0.01)$ & $0.77(0.01)$ \\
$\quad$ velocity $(\mu \mathrm{m} / \mathrm{s})( \pm$ SEM) & & & \\
Number of measurements & 986 & 880 & 1328 \\
Number of puncta & 298 & 328 & 528 \\
Number of axons & 24 & 27 & 36 \\
\hline
\end{tabular}

Cultured embryonic hippocampal neurons were transfected with IC-1 siRNA by electroporation, cultured on coverslips for $3 \mathrm{~d}$, and then transfected with either IC-1B-mRFP wild-type, dephosphomimic $880 \mathrm{~A}$, or phosphomimic mutant $580 \mathrm{D}$ with calcium phosphate and imaged the next day. The siRNA oligonucleotide reduced the amount of endogenous IC -1 in the cells to minimize WT compensation for mutant phenotypes. There was no significant difference in the mean puncta density or interval retrograde velocity when the phospho- and dephospho-IC-1B S80 mutants were compared.

puncta were significantly less likely to colocalize with TrkA puncta compared to WT or the IC-2CB S81D phosphomimic mutant in PC12 cells (Fig. 6C,D). These results are consistent with the hypothesis that IC phosphorylation enhances dynein binding to signaling endosomes.

While there was a significant decrease in the extent of colocalization of the dephosphomimic mutants with Trks, there was some residual colocalization. To determine whether this was because the S/A mutants were not perfect mimics, we investigated the association of dynein with immunoaffinity-purified Trkcontaining organelles (Fig. $6 E$ ). We first quantified the ratio of intensities of the phospho-IC to the pan-IC. No difference was observed when the cytosol (S1) and crude total membrane fractions (P2) were compared. However, there was a 2.4-fold enrichment of the phosphodynein associated with immunopurified Trk-containing membrane-bounded organelles relative to the cytosol and crude total membrane fraction (Fig. 6E). We then compared the amount of phospho-IC on organelles purified from NGF-treated cells and cells that were pretreated with the MEK1/2 inhibitor UO126 before the addition of NGF. We found that pretreatment with UO126 substantially reduced the amount of phospho-IC dynein found in the crude total membrane fraction (P2) and the Trk-containing organelles (Fig. 6F). When the intensities of the pan-IC antibody signals were quantified, we found that pretreatment of cells with UO126 decreased by $60 \%$ the amount of all ICs copurifying with Trk-containing vesicles (Fig. 6F). Most of the decrease in total IC associated with Trkcontaining organelles isolated from UO126-treated cells was due to the loss of $92 \%$ of the upper, phospho-IC band. Importantly, there was no compensatory increase in the level of the lower, dephospho-IC band in the UO126-treated Trk-containing organelles; rather, there was also a slight decrease $(21 \%)$ in the amount of the dephospho-IC band in the UO126-treated Trkcontaining organelles. We also observed that after pretreatment of cells with the MEK inhibitor UO126, there was almost no activated ERK1/2 associated with the Trk-containing organelles.

The role of intermediate chain phosphorylation for dynein binding to Rab7-positive endosomes and mitochondria

The enrichment of phosphodynein on Trk-containing organelles, but not the crude total membrane pellet, suggested that this phosphorylation site was not used by all classes of membranebounded organelle for dynein recruitment. We therefore analyzed the colocalization of dynein with two other organelles in cultured neurons, Rab7-positive endosomes and mitochondria. We found that in living axons, Rab7 extensively colocalizes with IC-1B and that the two markers often moved together in the 
A

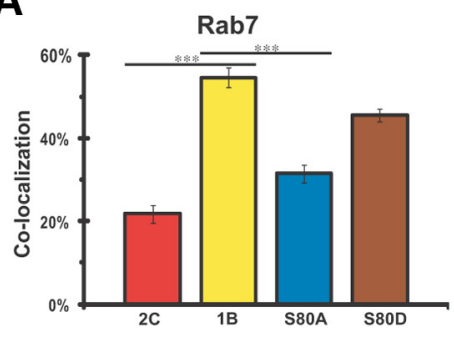

C

IC Isoforms IC-1B Mutants
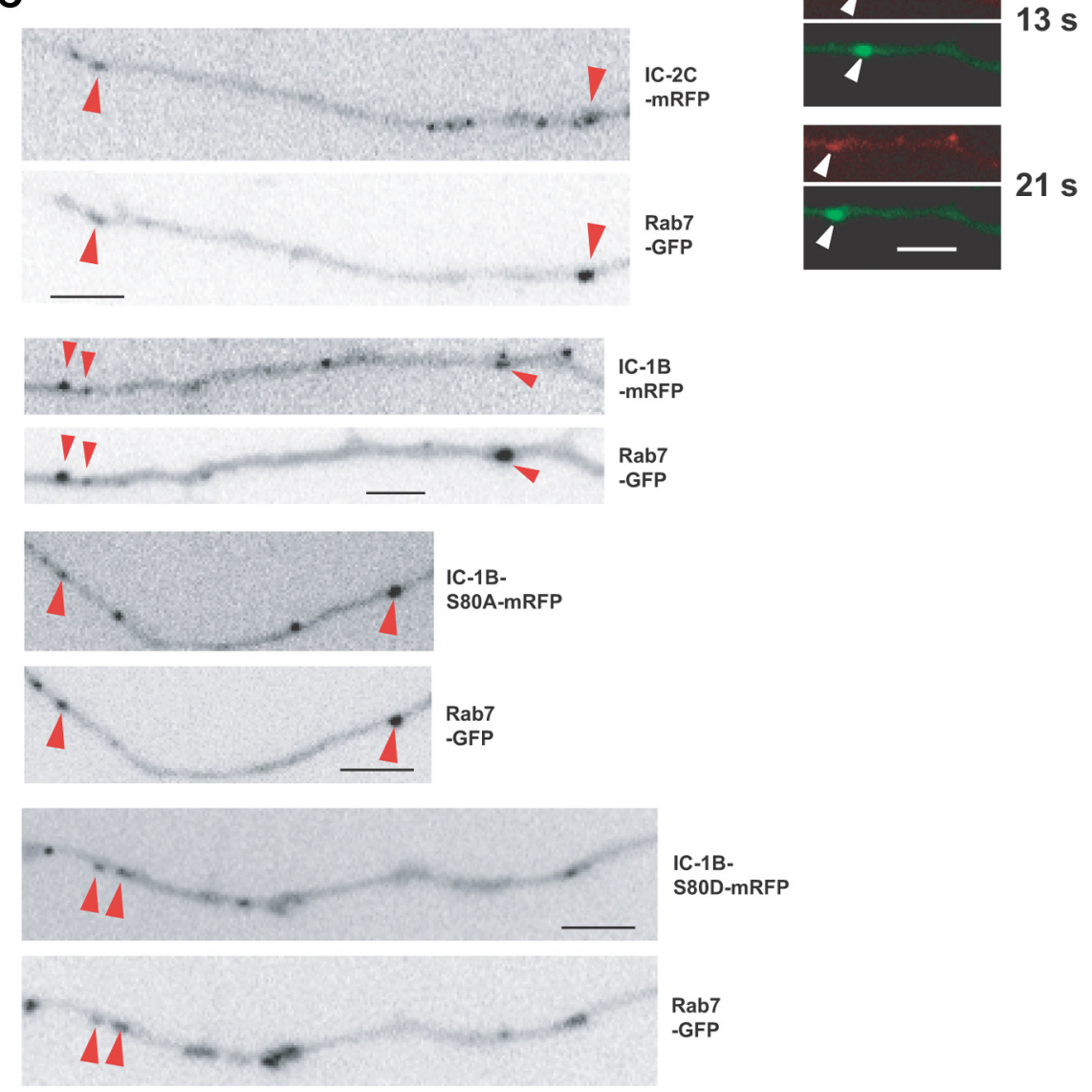

Figure 7. Dynein binding to Rab7-positive endosomes utilizes $\$ 80$ phospho-IC-1. A, Rab7-positive endosomes are more likely to associate with cytoplasmic dynein with the IC-1B isoform, and the dephosphomimic IC-1B S80A mutation reduces the level of dynein colocalization with Rab7 in cultured neurons. Cultured embryonic hippocampal neurons were cotransfected with Rab7-GFP and either IC-2C-mRFP, IC-1B WT, dephosphomimic IC-1B S80A, or phosphomimic mutant IC-1B S80D. Axons of living cells were simultaneously imaged in the GFP and RFP channels with DualView, and the percentage of colocalizing dynein and Rab7 puncta was quantified. IC-1B is significantly more likely than IC-2C to colocalize with Rab7 ( ${ }^{* * *} p<0.001$, Student's $t$ test). Numbers of puncta were $176 \mathrm{IC}-2 \mathrm{C}$ and 224 Rab7, and $144 \mathrm{IC}-1 \mathrm{~B}$ and 170 Rab7. The dephosphomimic S80A shows significantly less colocalization with Rab7 than WT IC-1B (*** $p<0.001$, Student's $t$ test). Numbers of puncta analyzed were 203 IC-1B S80A and 183 Rab7, and 242 IC-1B S80D and 263 Rab7. The difference between WT and S80D phosphomimic mutant was not significant. $B$, Live cell imaging of the retrograde transport of Rab7 by dynein with the IC-1B isoform. Cultured embryonic hippocampal neurons were cotransfected with Rab7-GFP and IC-1B WT. The pairs of images are aligned portions of DualView frames of a movie taken of an axon of a living cell, and the white arrowheads point to IC-1B-mRFP (top panel of each pair; red) and Rab7-GFP (bottom panel of each pair; green) puncta that move concomitantly in the axon. The time intervals between the pairs of images are indicated on the right. The direction of movement is retrograde (cell body to the left). The velocity of movement of the spot was $0.35 \mu$ s. $\boldsymbol{C}$, Colocalization of Rab7 and IC isoforms in cultured hippocampal neurons. Neurons were cotransfected as described for $\boldsymbol{A}$, and movies of axons of living cells were made with the GFP and mRFP signals collected simultaneously using DualView. The pairs of panels are from single DualView frames with the indicated IC-mRFP isoform (top of each pair) and Rab7-GFP (bottom of each pair) signals aligned and the puncta displayed in reverse contrast. Red arrowheads identify puncta that colocalize. Puncta that showed only partial overlap or that did not colocalize in all frames are not identified. In these examples, $25 \%$ of the IC-2C WT colocalized with Rab7, 50\% of the IC-1B WT colocalized with Rab7, 33\% of the IC-1B S80A colocalized with Rab7, and 40\% of the IC-1B S80D colocalized with Rab7. Scale bars: $5 \mu \mathrm{m}$. Error bars indicate SEM. retrograde direction (Fig. $7 A-C$ ). When the extent of colocalization of the IC-2C and IC-1B dynein intermediate chain isoforms with Rab7 puncta was quantified, it was observed that dynein with IC-1B was significantly more likely to associate with Rab7 than dynein with IC-2C (Fig. $7 A, C$ ). We then compared the colocalization of the IC-1B S80 phosphomimic and dephosphomimic mutants with Rab7 and found that, as for signaling endosomes, the IC-1B S80A dephosphomimic mutant was significantly less likely to colocalize with Rab7-positive endosomes in hippocampal axons when compared to WT or the S80D phosphomimic mutant (Fig. $7 A, C)$. This demonstrated that IC phosphorylation enhances dynein binding to Rab7-positive endosomes.

We next investigated dynein association with mitochondria. It was observed that dynein with IC-2C was significantly more likely to colocalize with mitochondria than dynein with IC-1B (Fig. $8 A, B$ ). We further found that the extent of colocalization of dynein with either the IC-2C S81 phosphomimic or dephosphomimic mutants with mitochondria was not significantly different from that of wild-type dynein (Fig. 8A,B). These data demonstrate that phosphorylation of IC-2C S81 is not necessary for dynein binding to mitochondria, and therefore that not all membrane-bounded organelles use ERK phosphorylation of the ICs to regulate dynein recruitment.

\section{IC-1 S80 phosphomimic mutants have} similar retrograde kinetics

Our data demonstrated that ERK $1 / 2$ phosphorylation was important for dynein binding to specific types of organelles. We next sought to determine whether the IC phosphorylation also modulated dynein kinetics by examining the kinetic properties of dynein complexes with the IC-1B S80A and S80D mutants in axons. No significant difference was observed between the velocities of the phosphomimic and dephosphomimic IC mutations, although there was a small difference between the mean velocities of both mutants and WT (Table 2). These data are consistent with the observation that not all organelles use phosphorylation on this serine for dynein recruitment. These data also suggest that IC phosphorylation, though enhancing dynein binding to Trkcontaining signaling endosomes, had no effect on dynein motor activity.

The role of IC phosphorylation in retrograde axonal transport

To examine the role of IC phosphorylation for dynein function, we used the 


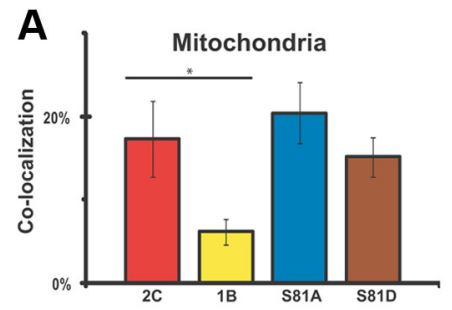

IC Isoforms IC-2C Mutants

\section{B}
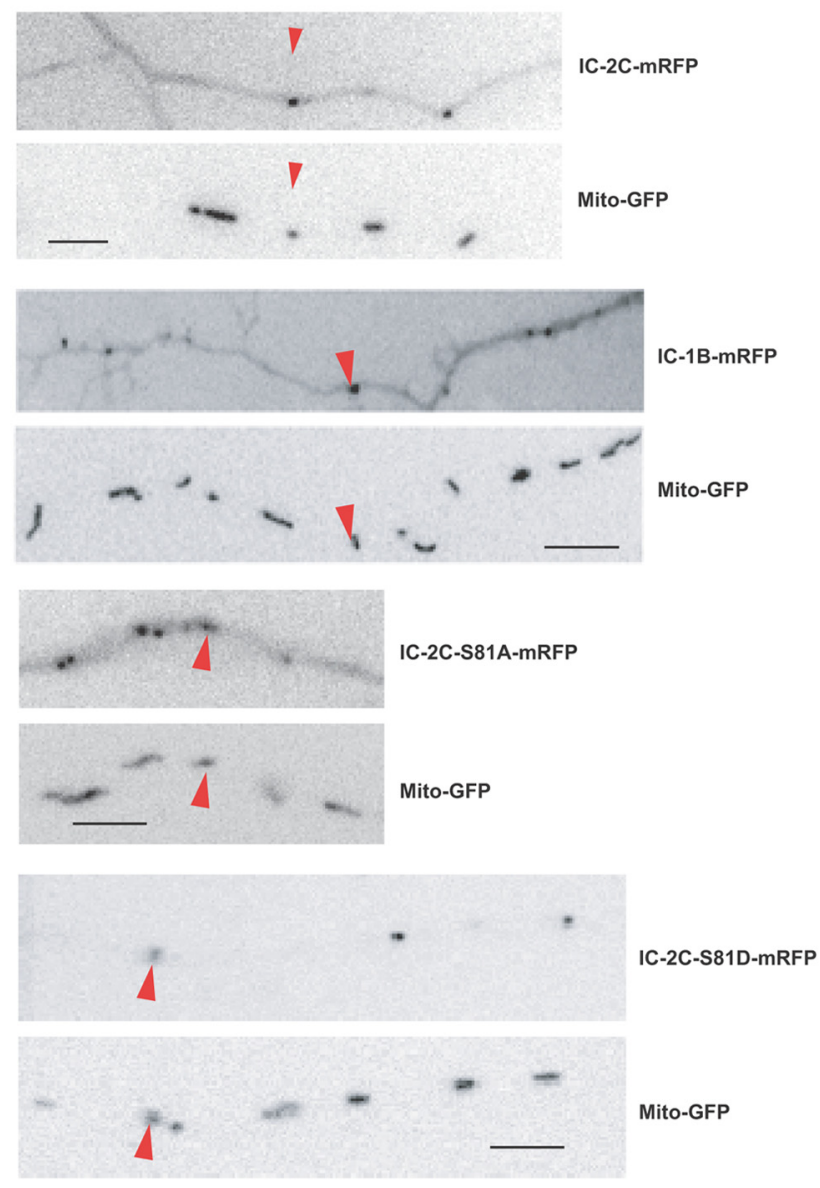

Figure 8. Dynein binding to mitochondria utilizes $I C-2$ and is independent of $\$ 81$ phosphorylation. $A$, Mitochondria are more likely to colocalize with cytoplasmic dynein with the IC-2C isoform, and the colocalization is not sensitive to IC-2C S81 phosphorylation. Cultured embryonic neurons were depleted of endogenous IC -2 by siRNA and cotransfected with Mito-GFP and either IC-1B-mRFP, IC-2C-mRFP, dephosphomimic IC-2C S81A, or phosphomimic mutant IC-2C S81D. Axons of living cells were simultaneously imaged with DualView in the GFP and RFP channels, and the percentage of overlapping dynein and mitochondria puncta was quantified. IC-2C is significantly more likely than IC- 1 B to colocalize with mitochondria $\left(^{*} p<0.03\right.$, Student's $t$ test). Number of puncta were 185 IC $-2 C$ and 425 mitochondria; 172 IC-1B and 274 mitochondria; IC-2C S81A, 105 dynein, and 240 mitochondria; and IC-2C S81D, 276 dynein, and 376 mitochondria. There was no significant difference in colocalization with mitochondria between WT IC-2C and either mutant (Student's $t$ test). B, Colocalization of mitochondria and IC-2C dynein in cultured hippocampal neurons. Neurons were cotransfected as described in $\boldsymbol{A}$, and movies of axons of living cells were made with the GFP and mRFP signals collected simultaneously using DualView. The pairs of panels are from single DualView frames with the indicated IC-mRFP isoform (top of each pair) and Mito-GFP (bottom of each pair) signals aligned and the puncta displayed in reverse contrast. Red arrowheads identify puncta that colocalize. Puncta that only showed partial overlap or that did not colocalize in all frames are not identified. In these examples, $14 \%$ of the IC-1B WT colocalized with mitochondria, $50 \%$ of the IC-2C WT colocalized with mitochondria, $20 \%$ of the IC-2C S81A colocalized with mitochondria, and $33 \%$ of the IC-2C S81D colocalized with mitochondria. Scale bars: $5 \mu \mathrm{m}$. Error bars indicate SEM.
Table 3. The effect of ERK1/2 inhibition on TrkB and Rab7 transport and colocalization with dynein

\begin{tabular}{|c|c|c|c|c|c|c|}
\hline & \multicolumn{3}{|l|}{ TrkB } & \multicolumn{3}{|l|}{ Rab7 } \\
\hline & Control & U0126 & $\mathrm{U} / \mathrm{C}$ & Control & U0126 & $\mathrm{U} / \mathrm{C}$ \\
\hline $\begin{array}{l}\text { Mean dynein density (punc- } \\
\mathrm{ta} / \mu \mathrm{m} \text { of axon length) } \\
( \pm \mathrm{SEM})^{a}\end{array}$ & $0.1(0.01)$ & $0.13(0.01)$ & 1.30 & $0.14(0.01)$ & $0.2(0.01)$ & ) 1.43 \\
\hline $\begin{array}{l}\text { Excursive motility (\% of total } \\
\text { puncta) }( \pm \text { SEM })^{b}\end{array}$ & $17.8(2.1)$ & $10.8(1.2)$ & 0.61 & $13.1(2.4)$ & $5.3(1.3)$ & 0.40 \\
\hline $\begin{array}{l}\text { Retrograde motility (\% of } \\
\text { total puncta) }( \pm \text { SEM) }\end{array}$ & $10.7(1.6)$ & $5.9(1.5)$ & 0.55 & $10.2(2.0)$ & $3.6(1.0)$ & 0.35 \\
\hline Number of puncta & 326 & 273 & & 489 & 467 & \\
\hline Number of axons & 37 & 18 & & 28 & 20 & \\
\hline $\begin{array}{l}\text { Colocalization with IC-1B (\% } \\
\text { puncta) }( \pm \text { SEM })^{d}\end{array}$ & $21.7(5.7)$ & $5.9(2.0)$ & 0.27 & $54.6(4.8)$ & $42.4(3.2)$ & 0.78 \\
\hline Number of $1 \mathrm{~B}$ puncta & 83 & 532 & & 144 & 495 & \\
\hline Number of cargo puncta & 96 & 489 & & 170 & 692 & \\
\hline Number of axons & 26 & 96 & & 17 & 61 & \\
\hline
\end{tabular}

Cultured hippocampal neurons were transfected with either TrkB-GFP or Rab7-GFP, or they were cotransfected with 1B-mRFP and TrkB-GFP or Rab7-GFP. Axons in control or U0126-treated dishes were imaged, and the indicated measurements were obtained as described in Materials and Methods. $U / C$, Ratio of indicated measurement from U0126-treated cells compared to control cells.

${ }^{a}$ Addition of $\mathrm{U} 0126$ caused a significant increase in the density (number of puncta per micrometer of axon length) of both TrkB and $\operatorname{Rab7}$ ( $p<0.02$ and $p<0.002$, respectively; Student's $t$ test).

${ }^{b}$ Addition of U0126 significantly reduced the excursive motility of TrkB and Rab7 ( $p<0.006$ and 0.007 , respectively; Student's $t$ test).

'The retrograde motility of Rab7 was significantly decreased in the presence of $\mathrm{U} 0126(p<0.005$, Student's $t$ test) ${ }^{d}$ Addition of 00126 caused a significant decrease in the colocalization of IC-1B dynein with TrkB and Rab7 $(p<0.02$ and $p<0.04$, respectively; Student's $t$ test).

MEK inhibitor UO126 to reduce the level of IC phosphorylation in cultured neurons (Fig. $4 \mathrm{H}$ ) and characterized the effects of the drug on the transport of Rab7- and TrkB-containing organelles and their colocalization with IC-1B (Table 3). After a $30 \mathrm{~min}$ incubation with drug, IC phosphorylation was reduced $50 \%$ relative to cells grown under normal culture conditions, and 70\% compared to BDNF-treated cells (Fig. 4H). The addition of UO126 also significantly reduced the extent of colocalization of both TrkB and Rab7 with IC-1B (Table 3). In the presence of the inhibitor, a significant increase in the density of TrkB and Rab7 puncta in axons was observed (Table 3), a result consistent with a decrease in the number of axonal cargo moving in the retrograde direction. When the motility of Rab7 and TrkB puncta were examined in the presence of the drug, a significant reduction in excursive motility was observed for both TrkB and Rab7 puncta relative to control. In addition, there was a significant decrease in the number of Rab7 puncta moving in the retrograde direction. Also, only $55 \%$ as many TrkB puncta were moving in the retrograde direction in UO126-treated cells relative to control cells, but this was not found to be significant, possibly due to the distortion caused by the large, relatively immotile pool of TrkB on the axon surface and the presence of anterograde TrkB carrier vesicles (Table 3 ).

\section{IC phosphorylation and NGF-dependent neuronal survival}

Dynein is known to mediate long-distance neurotrophin survival signaling (Heerssen et al., 2004). We next sought to determine the role of S80 phosphorylation on NGF-dependent survival. Toward this end, we made use of cultured sympathetic neurons whose survival requires transport of NGF-TrkA endosomes. When cells were transfected with WT IC-1B-mRFP, there was no effect on cell survival compared to control transfected cells (Fig. 9). However, when cells were transfected with the dephosphomimic mutant IC-1B-S80A-mRFP, a significant decrease in NGF-dependent neuronal survival was observed. Thus, expres- 


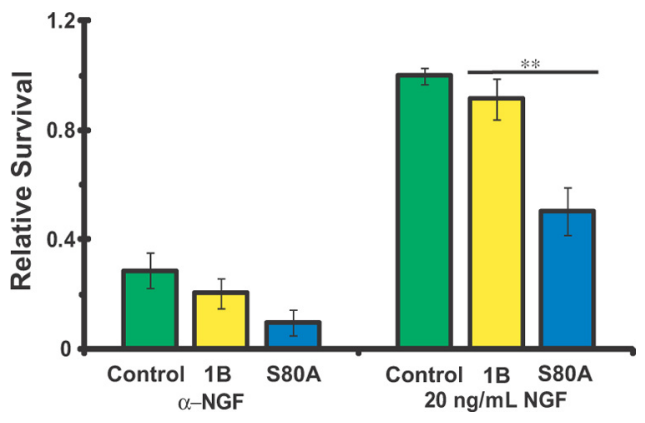

Figure 9. Expression of the dephospho-IC-1B S80A mutant in sympathetic neurons reduces NGF-dependent cell survival. Sympathetic neurons were cultured as described and transfected with either the IC-1B WT or S80A dephospho mutant by nucleofection, and the survival of the transfected cells in the presence of antibody to NGF in the absence of NGF ( $\alpha$-NGF) or presence of $20 \mathrm{ng} / \mathrm{ml}$ NGF was determined. When the S80A mutant was expressed, there was a $45 \%$ decrease in cell survival relative to WT transfected cells in the presence of NGF $\left({ }^{* *} p<0.003\right.$, Student's $t$ test, highly significant). Green, Control transfected cells; yellow, WT IC-1B-mRFP transfected cells; blue, IC-1B-S80A transfected cells. $n=6$ transfections with 122-182 cells for each bar. Error bars indicate SEM.

sion of an IC that cannot be phosphorylated on this specific site has a dominant-negative effect on neuronal survival. This observation supports a role for phosphorylation of this site in recruiting dynein to Trk-containing signaling endosomes. These data, in combination with the reduced colocalization of the dephosphomimic IC-1B mutant with the two cargos and the reduced amount of dynein on immunoaffinity-purified Trk-containing organelles from UO126-treated cells, all support a model in which phosphorylation enhances dynein binding to organelles for retrograde transport. The finding that the dephosphomimic and phosphomimic mutations had similar kinetic properties suggests that IC phosphorylation does not modulate motor kinetics.

\section{Discussion}

An essential step in neurotrophin survival signaling is the transport of Trk-containing endosomes from the axon to the cell body. We identified a mechanism used to recruit the retrograde transport motor, cytoplasmic dynein, to the signaling endosome. In two model systems, PC12 cells and neurons, a signaling cascade beginning with neurotrophin binding to Trk and terminating in ERK1/2 resulted in phosphorylation of the cytoplasmic dynein IC subunit on a novel conserved serine that enhanced dynein recruitment to the signaling endosome (Fig. 10). Although PC12 cells and hippocampal neurons use dynein complexes with different IC isoforms to bind to signaling endosomes, the two systems use a common regulatory mechanism based on conserved IC phosphorylation.

Our data demonstrate that phosphorylation on this serine enhances dynein binding to Trk signaling endosomes and Rab7containing endosomes. Using live cell imaging studies, we found that the dephospho-IC mimic mutants show significantly decreased colocalization with fluorescent markers for the two organelles in PC12 cells and hippocampal neurons. Expression of the dephosphomimic mutant IC significantly reduced NGFdependent cell survival of sympathetic neurons. Also, phosphoICs were enriched on affinity-purified Trk-containing organelles, and the MEK inhibitor significantly decreased total dynein association with the purified organelles.

In sensory neurons, the addition of neurotrophin to either cell bodies or distal axons leads to activation of ERK1/2 and ERK5 (Watson et al., 2001). Our inhibitor studies suggest that ERK5 does not phosphorylate the IC. Kinase prediction algorithms, specific pharmacological inhibition, in vitro phosphorylation, and in vivo expression of constitutively active MEK support the identification of ERK1/2 as the most likely kinase to phosphorylate the IC at this site. We also observed that maximal ERK1/2 activation (phosphorylation) preceded maximal dynein phosphorylation in PC12 cells and cortical neurons. The time differential may indicate that other components are involved in IC phosphorylation (Lewis et al., 2000; Wu et al., 2001; Huang and Reichardt, 2003). Interestingly, while IC phosphorylation levels were stable for at least $60 \mathrm{~min}$ in both cell types, the level of neurotrophin-stimulated ERK1/2 phosphorylation in PC12 cells decreased gradually. We also observed that there is phosphorylated IC in PC12 cells that had not been stimulated by NGF and in cells that had low levels of active ERK1/2. These data suggest that only a relatively small amount of active ERK1/2 may be necessary to regulate IC phosphorylation, or that the turnover of phosphate on the IC may be relatively slow, perhaps because it is protected by binding to another protein (Fig. 10). Alternatively, other growth factors or signaling pathways may also be involved in dynein phosphorylation at this site (Vaudry et al., 2002; Reichardt, 2006). While further investigation will be necessary to identify the additional components involved in the regulation of IC phosphorylation, our data suggest a model in which phosphorylation on this site enhances dynein binding to signaling endosomes for their transport (Fig. 10).

Phosphorylation of dynein subunits has been implicated previously in dynein regulation (Dillman and Pfister, 1994; Lin et al., 1994; Niclas et al., 1996; Dell et al., 2000; Addinall et al., 2001; Salata et al., 2001; Vaughan et al., 2001; Whyte et al., 2008). However, previous studies suggested that phosphorylation inhibits dynein binding to organelles. In Xenopus mitotic extracts, phosphorylation of light intermediate chains was correlated with decreased dynein binding to uncharacterized membrane-bounded organelles, and phosphorylation of IC-2C at S84 decreased dynein binding to Golgi and dextran-positive membranes in fibroblasts (Niclas et al., 1996; Vaughan et al., 2001). In contrast, our results indicate that IC phosphorylation, at the site we identified, enhances dynein binding to some cargos.

Our data suggest that phosphorylation on this specific site of the IC is not involved in in regulating dynein binding to all organelles, as it is not required for dynein colocalization with mitochondria. Rather, we predict that mitochondria and other organelle types will be found to use other mechanisms to recruit dynein. The existence of other mechanisms for dynein recruitment to organelles would account for our finding that while phospho-IC is enriched on Trk-containing organelles, it is not enriched in the crude total membrane fraction. The model would also account for the observation that some dephosphodynein remains associated with Trk organelles immunopurified from ERK-inhibited cells. One characteristic of the axon as a model system is that all proteins that become retrograde cargo, and dynein itself, must first be delivered to the axon terminal by anterograde transport, and it has been observed that most organelles move in both directions. The immunoaffinity procedure should purify both Trk-containing signaling endosomes that are moved in the retrograde direction by dynein and Trk-containing carrier organelles that are delivered to the axon plasma membrane by members of the kinesin family (Gomes et al., 2006; Arimura et al., 2009; Ascaño et al., 2009). This possibility is consistent with the description of organelles purified by immunoaffinity to the Jip3 homolog, Sunday Driver (Abe et al., 2009). Immunoaffinity purification yielded organelles with two distinct morphologies as characterized by electron microscopy, and mass 


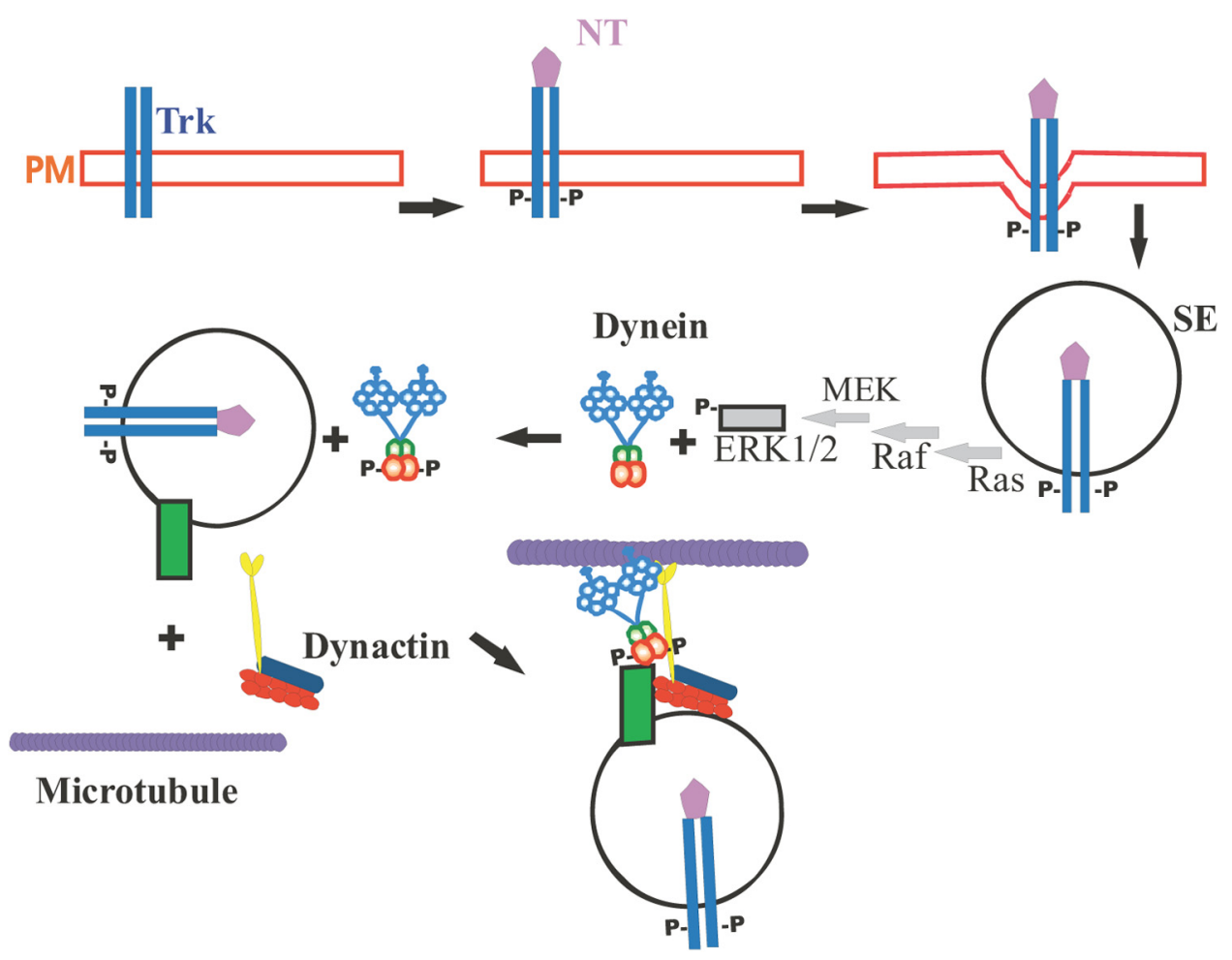

Figure 10. Model for ERK1/2 phosphorylation of ICs regulating cytoplasmic dynein binding to endosomes in response to neurotrophin. The Trk kinase is a transmembrane neurotrophin (NT) receptor resides in the plasma membrane (PM). Neurotrophin binding induces Trk autophosphorylation on the cytoplasmic tail and internalization as a signaling endosome (SE), with neurotrophin remaining bound to the Trk. Downstream of Trk, Ras is activated by GTP binding, and it activates Raf, which activates MEK, which phosphorylates and activates the ERK1/2 MAP kinase. ERK1/2 phosphorylates the cytoplasmic dynein IC-1 and IC-2. This enhances dynein binding to the signaling endosome through a factor (green box) in addition to dynactin.

spectrometry provided evidence for the presence of both endosomal and anterograde carrier membrane proteins in the immunoprecipitates. If dynein were bound to the anterograde carrier organelles through a mechanism that did not require ERK phosphorylation, then, consistent with our observations, approximately half of the Trk-containing organelles would be bound to ICs that were not phosphorylated on this site. However, we cannot rule out the possibility that there may be an alternate mechanism for recruiting dynein to the Trk-containing endosomes. This would also account for the observation that some sympathetic neurons survive when the dephospho-IC mimic mutant is expressed. The observations that CK1 linked phosphorylation of the ICs is important for microtubule minus end-directed melanosome movement in amphibian melanophores (Ikeda et al., 2011) and that IC-2C phosphorylated at T89 binds to mammalian kinetochores (Whyte et al., 2008) are also consistent with dynein binding to organelles being regulated by several mechanisms.

We found that the kinetics of dynein complexes containing the dephosphomimic IC mutants were comparable to those of the phosphomimic mutants. This is consistent with the hypothesis that IC phosphorylation is one of several mechanisms used to link dynein to cargo and that it is not used to regulate dynein kinetics. Nevertheless, since IC phosphorylation enhances dynein binding to both the Rab7 and Trk organelles, it is important for their transport. When IC phosphorylation is reduced by the MEK inhibitor UO126, there is less dynein associated with Rab7 and TrkB endosomes, and both cargo organelles accumulate in axons and exhibit less motility.

Models of mechanisms to regulate dynein binding to organelles postulate changes to dynein, changes to proteins on the organelle, or both. Our results indicate that at a minimum, IC phosphorylation enhances dynein binding to both the TrkB- and Rab7-containing endosomes. The dynactin complex is thought to link dynein to membrane-bounded organelles and other cargos, since the p150 subunit of dynactin binds the dynein ICs (Vaughan and Vallee, 1995; Karki and Holzbaur, 1999; Schroer, 2004; Kardon and Vale, 2009; Akhmanova and Hammer, 2010). Dynactin is also important for dynein motor activity (CulverHanlon et al., 2006), and it has been suggested that dynactin's role is motor coordination, not the attachment of dynein to the membrane (Haghnia et al., 2007). It was shown previously that organelle-specific membrane proteins are involved in recruiting dynactin to membrane-bounded organelles, including RILP (Rab7-interacting lysosomal protein) (Jordens et al., 2001; Kardon and Vale, 2009; Akhmanova and Hammer, 2010). However, we found no difference in the ability of bacterially expressed dephospho-WT IC-2C or IC-2C S81 phosphomimic to bind dynactin in pulldown experiments (A. K. Pullikuth and A. D. Catling, unpublished observations), and similar results with the S81 phosphomimic and dephosphomimic mutants were reported using a solid phase assay (Vaughan et al., 2001). These data demonstrate that ERK1/2 phosphorylation of the ICs does not alter dynein binding to dynactin. Thus, while the dynein-dynactin interaction is important for dynein function, a yet-to-beidentified additional component must be also involved in dynein binding to endosomes (Fig. 10, green box). It has also been suggested that one of the dynein light chains, DYNLT1 (Tctex1) binds to all three Trk growth factor receptors (Yano et al., 2001). However, this was independent of Trk activation and thus IC phosphorylation. It also does not account for the specificity for dynein complexes with IC-1 binding to signaling endosomes in neurons (Ha et al., 2008). 
In summary, our data support a model in which cells use different mechanisms to recruit dynein to different organelles. Dynein recruitment to TrkB signaling endosomes, but not mitochondria, is enhanced by the phosphorylation of the IC subunits by ERK1/2 (Fig. 10). Phosphorylation is permissive for cytoplasmic dynein recruitment to the organelles, but not for the kinetic properties of the motor. For Trk signaling endosomes, the regulatory pathway begins with neurotrophin binding to Trk kinase and subsequent activation of the MAP kinase pathway. Thus, the Trk-containing signaling endosome regulates its own retrograde transport.

\section{References}

Abe N, Almenar-Queralt A, Lillo C, Shen Z, Lozach J, Briggs SP, Williams DS, Goldstein LS, Cavalli V (2009) Sunday driver interacts with two distinct classes of axonal organelles. J Biol Chem 284:34628-34639. CrossRef Medline

Addinall SG, Mayr PS, Doyle S, Sheehan JK, Woodman PG, Allan VJ (2001) Phosphorylation by cdc2-CyclinB1 kinase releases cytoplasmic dynein from membranes. J Biol Chem 276:15939-15944. CrossRef Medline

Akhmanova A, Hammer JA 3rd (2010) Linking molecular motors to membrane cargo. Curr Opin Cell Biol 22:479-487. CrossRef Medline

Altar CA, DiStefano PS (1998) Neurotrophin trafficking by anterograde transport. Trends Neurosci 21:433-437. CrossRef Medline

Arévalo JC, Pereira DB, Yano H, Teng KK, Chao MV (2006) Identification of a switch in neurotrophin signaling by selective tyrosine phosphorylation. J Biol Chem 281:1001-1007. Medline

Arimura N, Kimura T, Nakamuta S, Taya S, Funahashi Y, Hattori A, Shimada A, Ménager C, Kawabata S, Fujii K, Iwamatsu A, Segal RA, Fukuda M, Kaibuchi K (2009) Anterograde transport of TrkB in axons is mediated by direct interaction with Slp1 and Rab27. Dev Cell 16:675-686. CrossRef Medline

Ascaño M, Richmond A, Borden P, Kuruvilla R (2009) Axonal targeting of Trk receptors via transcytosis regulates sensitivity to neurotrophin responses. J Neurosci 29:11674-11685. CrossRef Medline

Bain J, McLauchlan H, Elliott M, Cohen P (2003) The specificities of protein kinase inhibitors: an update. Biochem J 371:199-204. CrossRef Medline

Bain J, Plater L, Elliott M, Shpiro N, Hastie CJ, McLauchlan H, Klevernic I, Arthur JS, Alessi DR, Cohen P (2007) The selectivity of protein kinase inhibitors: a further update. Biochem J 408:297-315. CrossRef Medline

Brewer GJ, Torricelli JR, Evege EK, Price PJ (1993) Optimized survival of hippocampal neurons in B27-supplemented Neurobasal, a new serumfree medium combination. J Neurosci Res 35:567-576. CrossRef Medline

Bronfman FC, Tcherpakov M, Jovin TM, Fainzilber M (2003) Ligandinduced internalization of the $\mathrm{p} 75$ neurotrophin receptor: a slow route to the signaling endosome. J Neurosci 23:3209-3220. Medline

Catling AD, Schaeffer HJ, Reuter CW, Reddy GR, Weber MJ (1995) A proline-rich sequence unique to MEK1 and MEK2 is required for raf binding and regulates MEK function. Mol Cell Biol 15:5214-5225. Medline

Chang MY, Son H, Lee YS, Lee SH (2003) Neurons and astrocytes secrete factors that cause stem cells to differentiate into neurons and astrocytes, respectively. Mol Cell Neurosci 23:414-426. CrossRef Medline

Clary DO, Reichardt LF (1994) An alternatively spliced form of the nerve growth factor receptor TrkA confers an enhanced response to neurotrophin 3. Proc Natl Acad Sci U S A 91:11133-11137. CrossRef Medline

Crackower MA, Sinasac DS, Xia J, Motoyama J, Prochazka M, Rommens JM, Scherer SW, Tsui LC (1999) Cloning and characterization of two cytoplasmic dynein intermediate chain genes in mouse and human. Genomics 55:257-267. CrossRef Medline

Culver-Hanlon TL, Lex SA, Stephens AD, Quintyne NJ, King SJ (2006) A microtubule-binding domain in dynactin increases dynein processivity by skating along microtubules. Nat Cell Biol 8:264-270. CrossRef Medline

Davies SP, Reddy H, Caivano M, Cohen P (2000) Specificity and mechanism of action of some commonly used protein kinase inhibitors. Biochem J 351:95-105. CrossRef Medline

Deckwerth TL, Johnson EM Jr (1993) Temporal analysis of events associated with programmed cell death (apoptosis) of sympathetic neurons deprived of nerve growth factor. J Cell Biol 123:1207-1222. CrossRef Medline
Dell KR, Turck CW, Vale RD (2000) Mitotic phosphorylation of the dynein light intermediate chain is mediated by cdc2 kinase. Traffic 1:38-44. CrossRef Medline

Deppmann CD, Mihalas S, Sharma N, Lonze BE, Niebur E, Ginty DD (2008) A model for neuronal competition during development. Science 320: 369-373. CrossRef Medline

Dillman JF 3rd, Pfister KK (1994) Differential phosphorylation in vivo of cytoplasmic dynein associated with anterogradely moving organelles. J Cell Biol 127:1671-1681. CrossRef Medline

Dillman JF 3rd, Dabney LP, Karki S, Paschal BM, Holzbaur EL, Pfister KK (1996) Functional analysis of dynactin and cytoplasmic dynein in slow axonal transport. J Neurosci 16:6742-6752. Medline

Eblen ST, Slack-Davis JK, Tarcsafalvi A, Parsons JT, Weber MJ, Catling AD (2004) Mitogen-activated protein kinase feedback phosphorylation regulates MEK1 complex formation and activation during cellular adhesion. Mol Cell Biol 24:2308-2317. CrossRef Medline

Feng Y, Press B, Wandinger-Ness A (1995) Rab 7: an important regulator of late endocytic membrane traffic. J Cell Biol 131:1435-1452. CrossRef Medline

Ginty DD, Segal RA (2002) Retrograde neurotrophin signaling: Trk-ing along the axon. Curr Opin Neurobiol 12:268-274. CrossRef Medline

Gomes RA, Hampton C, El-Sabeawy F, Sabo SL, McAllister AK (2006) The dynamic distribution of TrkB receptors before, during, and after synapse formation between cortical neurons. J Neurosci 26:11487-11500. CrossRef Medline

Goslin K, Asmussen H, Banker G (1998) Rat hippocampal neurons in lowdensity culture. In: Culturing nerve cells, Ed 2 (Banker G, Goslin K, eds), pp 339-370. Cambridge. MA: MIT.

Grimes ML, Zhou J, Beattie EC, Yuen EC, Hall DE, Valletta JS, Topp KS, LaVail JH, Bunnett NW, Mobley WC (1996) Endocytosis of activated TrkA: evidence that nerve growth factor induces formation of signaling endosomes. J Neurosci 16:7950-7964. Medline

Guignot J, Caron E, Beuzón C, Bucci C, Kagan J, Roy C, Holden DW (2004) Microtubule motors control membrane dynamics of Salmonellacontaining vacuoles. J Cell Sci 117:1033-1045. CrossRef Medline

Ha J, Lo KW, Myers KR, Carr TM, Humsi MK, Rasoul BA, Segal RA, Pfister KK (2008) A neuron-specific cytoplasmic dynein isoform preferentially transports TrkB signaling endosomes. J Cell Biol 181:1027-1039. CrossRef Medline

Haghnia M, Cavalli V, Shah SB, Schimmelpfeng K, Brusch R, Yang G, Herrera C, Pilling A, Goldstein LS (2007) Dynactin is required for coordinated bidirectional motility, but not for dynein membrane attachment. Mol Biol Cell 18:2081-2089. CrossRef Medline

He Y, Francis F, Myers KA, Yu W, Black MM, Baas PW (2005) Role of cytoplasmic dynein in the axonal transport of microtubules and neurofilaments. J Cell Biol 168:697-703. CrossRef Medline

Heerssen HM, Pazyra MF, Segal RA (2004) Dynein motors transport activated Trks to promote survival of target-dependent neurons. Nat Neurosci 7:596-604. CrossRef Medline

Hirokawa N, Niwa S, Tanaka Y (2010) Molecular motors in neurons: transport mechanisms and roles in brain function, development, and disease. Neuron 68:610-638. CrossRef Medline

Howe CL, Mobley WC (2005) Long-distance retrograde neurotrophic signaling. Curr Opin Neurobiol 15:40-48. CrossRef Medline

Huang EJ, Reichardt LF (2003) Trk receptors: roles in neuronal signal transduction. Annu Rev Biochem 72:609-642. CrossRef Medline

Huang SH, Duan S, Sun T, Wang J, Zhao L, Geng Z, Yan J, Sun HJ, Chen ZY (2011) JIP3 mediates TrkB axonal anterograde transport and enhances BDNF signaling by directly bridging TrkB with kinesin-1. J Neurosci 31:10602-10614. CrossRef Medline

Ikeda K, Zhapparova O, Brodsky I, Semenova I, Tirnauer JS, Zaliapin I, Rodionov V (2011) CK1 activates minus-end-directed transport of membrane organelles along microtubules. Mol Biol Cell 22:1321-1329. CrossRef Medline

Jiang M, Chen G (2006) High Ca2+-phosphate transfection efficiency in low-density neuronal cultures. Nat Protoc 1:695-700. CrossRef Medline

Jordens I, Fernandez-Borja M, Marsman M, Dusseljee S, Janssen L, Calafat J, Janssen H, Wubbolts R, Neefjes J (2001) The Rab7 effector protein RILP controls lysosomal transport by inducing the recruitment of dyneindynactin motors. Curr Biol 11:1680-1685. CrossRef Medline

Kardon JR, Vale RD (2009) Regulators of the cytoplasmic dynein motor. Nat Rev Mol Cell Biol 10:854-865. CrossRef Medline 
Karki S, Holzbaur EL (1999) Cytoplasmic dynein and dynactin in cell division and intracellular transport. Curr Opin Cell Biol 11:45-53. CrossRef Medline

Kuta A, Deng W, Morsi El-Kadi A, Banks GT, Hafezparast M, Pfister KK, Fisher EM (2010) Mouse cytoplasmic dynein intermediate chains: identification of new isoforms, alternative splicing and tissue distribution of transcripts. PLoS One 5:e11682. CrossRef Medline

Lee MK, Rebhun LI, Frankfurter A (1990a) Posttranslational modification of class III beta-tubulin. Proc Natl Acad Sci U S A 87:7195-7199. CrossRef Medline

Lee MK, Tuttle JB, Rebhun LI, Cleveland DW, Frankfurter A (1990b) The expression and posttranslational modification of a neuron-specific betatubulin isotype during chick embryogenesis. Cell Motil Cytoskeleton 17: 118-132. CrossRef Medline

Leopold PL, Pfister KK (2006) Viral strategies for intracellular trafficking: motors and microtubules. Traffic 7:516-523. CrossRef Medline

Lewis TS, Hunt JB, Aveline LD, Jonscher KR, Louie DF, Yeh JM, Nahreini TS, Resing KA, Ahn NG (2000) Identification of novel MAP kinase pathway signaling targets by functional proteomics and mass spectrometry. Mol Cell 6:1343-1354. CrossRef Medline

Lin SX, Ferro KL, Collins CA (1994) Cytoplasmic dynein undergoes intracellular redistribution concomitant with phosphorylation of the heavy chain in response to serum starvation and okadaic acid. J Cell Biol 127: 1009-1019. CrossRef Medline

Lo KW, Kan HM, Pfister KK (2006) Identification of a novel region of the cytoplasmic Dynein intermediate chain important for dimerization in the absence of the light chains. J Biol Chem 281:9552-9559. Medline

Miller FD, Kaplan DR (2001) On Trk for retrograde signaling. Neuron 32: 767-770. CrossRef Medline

Morfini G, Szebenyi G, Elluru R, Ratner N, Brady ST (2002) Glycogen synthase kinase 3 phosphorylates kinesin light chains and negatively regulates kinesin-based motility. EMBO J 21:281-293. CrossRef Medline

Myers KR, Lo KW, Lye RJ, Kogoy JM, Soura V, Hafezparast M, Pfister KK (2007) Intermediate chain subunit as a probe for cytoplasmic dynein function: Biochemical analyses and live cell imaging in PC12 cells. J Neurosci Res 85:2640-2647. CrossRef Medline

Niclas J, Allan VJ, Vale RD (1996) Cell cycle regulation of dynein association with membranes modulates microtubule-based organelle transport. J Cell Biol 133:585-593. CrossRef Medline

Obenauer JC, Cantley LC, Yaffe MB (2003) Scansite 2.0: proteome-wide prediction of cell signaling interactions using short sequence motifs. Nucleic Acids Res 31:3635-3641. CrossRef Medline

Pfister KK, Salata MW, Dillman JF 3rd, Torre E, Lye RJ (1996a) Identification and developmental regulation of a neuron-specific subunit of cytoplasmic dynein. Mol Biol Cell 7:331-343. Medline

Pfister KK, Salata MW, Dillman JF 3rd, Vaughan KT, Vallee RB, Torre E, Lye RJ (1996b) Differential expression and phosphorylation of the 74-kDa intermediate chains of cytoplasmic dynein in cultured neurons and glia. J Biol Chem 271:1687-1694. CrossRef Medline

Pfister KK, Shah PR, Hummerich H, Russ A, Cotton J, Annuar AA, King SM, Fisher EM (2006) Genetic analysis of the cytoplasmic dynein subunit families. PLoS Genet 2:e1. CrossRef Medline

Reichardt LF (2006) Neurotrophin-regulated signalling pathways. Philos Trans R Soc Lond B Biol Sci 361:1545-1564. CrossRef Medline

Salata MW, Dillman JF 3rd, Lye RJ, Pfister KK (2001) Growth factor regulation of cytoplasmic dynein intermediate chain subunit expression preceding neurite extension. J Neurosci Res 65:408-416. CrossRef Medline

Schroer TA (2004) Dynactin. Annu Rev Cell Dev Biol 20:759-779. CrossRef Medline

Segal RA, Bhattacharyya A, Rua LA, Alberta JA, Stephens RM, Kaplan DR, Stiles CD (1996) Differential utilization of Trk autophosphorylation sites. J Biol Chem 271:20175-20181. CrossRef Medline

Shevchenko A, Wilm M, Vorm O, Mann M (1996) Mass spectrometric sequencing of proteins silver-stained polyacrylamide gels. Anal Chem 68: 850-858. CrossRef Medline
Slack-Davis JK, Eblen ST, Zecevic M, Boerner SA, Tarcsafalvi A, Diaz HB, Marshall MS, Weber MJ, Parsons JT, Catling AD (2003) PAK1 phosphorylation of MEK1 regulates fibronectin-stimulated MAPK activation. J Cell Biol 162:281-291. CrossRef Medline

Songyang Z, Lu KP, Kwon YT, Tsai LH, Filhol O, Cochet C, Brickey DA, Soderling TR, Bartleson C, Graves DJ, DeMaggio AJ, Hoekstra MF, Blenis J, Hunter T, Cantley LC (1996) A structural basis for substrate specificities of protein Ser/Thr kinases: primary sequence preference of casein kinases I and II, NIMA, phosphorylase kinase, calmodulin-dependent kinase II, CDK5, and Erk1. Mol Cell Biol 16:6486-6493. Medline

Steffen W, Karki S, Vaughan KT, Vallee RB, Holzbaur EL, Weiss DG, Kuznetsov SA (1997) The involvement of the intermediate chain of cytoplasmic dynein in binding the motor complex to membranous organelles of Xenopus oocytes. Mol Biol Cell 8:2077-2088. Medline

Uchida A, Alami NH, Brown A (2009) Tight functional coupling of kinesin-1A and dynein motors in the bidirectional transport of neurofilaments. Mol Biol Cell 20:4997-5006. CrossRef Medline

Valdez G, Akmentin W, Philippidou P, Kuruvilla R, Ginty DD, Halegoua S (2005) Pincher-mediated macroendocytosis underlies retrograde signaling by neurotrophin receptors. J Neurosci 25:5236-5247. CrossRef Medline

Vallee RB, Williams JC, Varma D, Barnhart LE (2004) Dynein: an ancient motor protein involved in multiple modes of transport. J Neurobiol 58 : 189-200. CrossRef Medline

Vaudry D, Stork PJ, Lazarovici P, Eiden LE (2002) Signaling pathways for PC12 cell differentiation: making the right connections. Science 296:1648-1649. CrossRef Medline

Vaughan KT, Vallee RB (1995) Cytoplasmic dynein binds dynactin through a direct interaction between the intermediate chains and p150Glued. J Cell Biol 131:1507-1516. CrossRef Medline

Vaughan PS, Leszyk JD, Vaughan KT (2001) Cytoplasmic dynein intermediate chain phosphorylation regulates binding to dynactin. J Biol Chem 276:26171-26179. CrossRef Medline

Watson FL, Heerssen HM, Moheban DB, Lin MZ, Sauvageot CM, Bhattacharyya A, Pomeroy SL, Segal RA (1999) Rapid nuclear responses to targetderived neurotrophins require retrograde transport of ligand-receptor complex. J Neurosci 19:7889-7900. Medline

Watson FL, Heerssen HM, Bhattacharyya A, Klesse L, Lin MZ, Segal RA (2001) Neurotrophins use the Erk5 pathway to mediate a retrograde survival response. Nat Neurosci 4:981-988. CrossRef Medline

Whyte J, Bader JR, Tauhata SB, Raycroft M, Hornick J, Pfister KK, Lane WS, Chan GK, Hinchcliffe EH, Vaughan PS, Vaughan KT (2008) Phosphorylation regulates targeting of cytoplasmic dynein to kinetochores during mitosis. J Cell Biol 183:819-834. CrossRef Medline

Wiedenmann B, Franke WW (1985) Identification and localization of synaptophysin, an integral membrane glycoprotein of Mr 38,000 characteristic of presynaptic vesicles. Cell 41:1017-1028. CrossRef Medline

Wu C, Lai CF, Mobley WC (2001) Nerve growth factor activates persistent Rap1 signaling in endosomes. J Neurosci 21:5406-5416. Medline

Wu C, Ramirez A, Cui B, Ding J, Delcroix JD, Valletta JS, Liu JJ, Yang Y, Chu S, Mobley WC (2007) A functional dynein-microtubule network is required for NGF signaling through the Rap1/MAPK pathway. Traffic 8:1503-1520. CrossRef Medline

Yano H, Lee FS, Kong H, Chuang J, Arevalo J, Perez P, Sung C, Chao MV (2001) Association of Trk neurotrophin receptors with components of the cytoplasmic dynein motor. J Neurosci 21:RC125. Medline

Zareen N, Greene LA (2009) Protocol for culturing sympathetic neurons from rat superior cervical ganglia (SCG). J Vis Exp 23:e988. CrossRef Medline

Zhang W, St-Gelais F, Grabner CP, Trinidad JC, Sumioka A, MorimotoTomita M, Kim KS, Straub C, Burlingame AL, Howe JR, Tomita S (2009) A transmembrane accessory subunit that modulates kainate-type glutamate receptors. Neuron 61:385-396. CrossRef Medline 